\title{
Urbanization and environmental change during the economic transition on the Mongolian Plateau: Hohhot and Ulaanbaatar
}

\begin{abstract}
:
Driven by drastic socioeconomic changes in China and Mongolia, urbanization has become one of the most significant driving forces in the transformation of the Mongolian Plateau in the past 30 years. Using Hohhot and Ulaanbaatar as case studies, we developed a holistic approach to examine the socioeconomic and natural driving forces for urbanization and to investigate the impact on the urban environment. We used a multidisciplinary approach and relied on a variety of data sources to assess the changes of the landscape and environment of the two cities. We detected a rapid urbanization in Hohhot and Ulaanbaatar, both in terms of urban population growth and urban land expansion, from 1990 to 2010, with a much faster speed in 2000-2010. The local geo-physical conditions have constrained the spatial direction of expansion. Ulaanbaatar lagged behind Hohhot for about a decade when measured by indicators of urban population and urban land. Both cities have a degraded urban environment and a growing air pollution epidemic. While Hohhot had worse air pollution than Ulaanbaatar in the early 2000s, the gap between the two cities became smaller after 2010 .

The research presented here highlights the following as key determinants for urbanization and environmental change: (1) the co-evolution of urbanization, economic development, and environmental change; (2) the urbanization of transitional economies driven by the change of the economic structure, i.e., the development by both manufacturing and tertiary sectors and the change in the primary sector; and (3) the recent institutional changes and increased integration with the global economy.
\end{abstract}

Keywords: urbanization, environment, economic development, Mongolian Plateau 


\section{Funding sources:}

We would like to acknowledge the financial support from the National Aeronautics and Space Administration (NASA)'s Land Cover and Land Use Program through their grants to Michigan State University (NNX09AI32G, NNX15AD51G, and NNX14AD85G), the "Dynamics of Coupled Natural and Human Systems (CNH)" Program of the NSF (\#1313761), the Natural Science Foundation of China (31229001), and the Asian Development Bank (ADB) through the project "Urbanization in Asia". 


\section{Introduction}

As one of the most pronounced changes on the Mongolia Plateau in the past three decades, urbanization continues to affect the interactions of the human-natural system since the market reform in China in the 1980s and liberalization in Mongolia since the early 1990s (Qi et al., 2012; Chen et al., 2015a \& 2015b). Both Mongolia and Inner Mongolia have leapt into an urban era, fueled by the massive rural-urban migration that is reflected in the rapid expansion of urban built-up areas. This transformation has unleashed dramatic impacts on the environment within the cities as well as far beyond their administrative boundaries (Fan et al, 2013; Huang et al, 2013; John et al, 2013; Qi et al, 2012)

Urbanization in the Mongolian Plateau is highly associated with the economic development and transformation in the region. The ratio of the population that lives in an urban area to its total population, known as the urbanization ratio, increased in Mongolia from 52\% in 1980 to $70 \%$ in 2013 and from 23\% in 1980 to 59\% in 2013 in Inner Mongolia-higher than the average level in China (54\% in 2013) (World Bank, 2015). Corresponding to urban population growth is the rise and fall of employment opportunities in different sectors and the restructuring of the national/regional economy, particularly in urban areas, over recent decades (ADB, 2008; Schran, 2014). The primary economic sector, including grazing and agricultural activities, is located in rural areas, while the secondary and tertiary sectors, such as construction, manufacturing, and various types of services are located primarily in urban areas. Mongolia's Gross Domestic Product (GDP) per capita (GDPpc) doubled within three decades, increasing from \$692 USD in 1981 to \$1474 USD in 2011 (Chen et al., 2015b; World Bank, 2015). While the industrial contribution to GDP increased from $25 \%$ in 1980 to $37 \%$ in 2010 , value added from the service sector slightly decreased from $58 \%$ to $46 \%$ of GDP in the same period; thus, the primary sector had the same contribution of GDP (17\%) in Mongolia in 2010 as in 1980 (World Bank, 2015). Furthermore, a more dramatic change had occurred in Inner Mongolia. At the beginning of economic reform in 1978, Inner Mongolia had a GDPpc of \$206 that was distributed near even among the industries (i.e., 33\%, 45\%, and 22\% in). In 2010, the region reached a GDPpc of $\$ 9,677$, which is $\sim 47$ times of its 1978 level, with an annual growth rate of $13 \%$. As a result, Inner Mongolia had transformed into an economy with a stronger focus on non-primary sectors, distributing $9 \%, 55 \%$, and $36 \%$ of its GDP among the primary, secondary, and tertiary sectors, respectively.

Urban built-up areas, meanwhile, expanded at an unprecedented rate for major cities in Mongolia and Inner Mongolia. For example, Ulaanbaatar increased its urban built-up area from $82 \mathrm{~km}^{2}$ in 1990 to $142 \mathrm{~km}^{2}$ in 2010 , whereas Hohhot had more than doubled within 15 years, growing from $105 \mathrm{~km}^{2}$ in 1995 to $229 \mathrm{~km}^{2}$ in 2010; most expansion occurred in the first decade of the new millennium for both cities. This expansion did not come without a cost and the environmental impact of urban expansion and spatial transformation has since been placed on the residents. The severity of air, water, and soil pollution resulting from the urbanization and changed economic structure on the Mongolia Plateau, as well as their direct and indirect impacts on human health and ecosystem services, have been highlighted in various reports from international organizations such as the World Bank, the United Nations Development Program (UNDP) and in scholastic research. 
Despite being an important element in understanding the transformation of the Mongolia Plateau and its coupled human-natural system, current literature on urbanization and its drivers, as well as its environmental impact, have been limited. Past research on urban landscape and environmental change on the plateau tends to focus on one aspect, such as analyzing urban landuse change through RS/GIS (Amarbayasgalan, 2008; Amarsaikhan et al., 2009; Fan et al, 2013), its driving forces (Tsogtsaikhan, 2003), rural to urban migration (Miller, 2013; Tsogtsaikhan, 2003; Wang, 1997), the efficiency of land use (Du, 2003; Mei and Hai, 2009; Mei and Han, 2010; Shen, 2004; Sun et al., 2010), evaluation of environment change (Dong et al., 2008; Ji et al., 2009; Luo, 2009; Sun et al., 2005; Zhang et al., 2010; Amarsaikhan et al., 2008, 2009, 2011; Bagan et al., 2009), or the consequences on the health of urban residents (Allen et al., 2013; Bolormaa, 2011; Dong et al., 2008; Guttikunda et al., 2007; Sonomjamts et al., 2014; UNDP, 2011; Warburton et al., 2013; World Bank, 2004). To date, there has not been an integrated assessment of urbanization and the consequential impacts on the urban environment. Using Hohhot and Ulaanbaatar as case studies, we took a holistic approach and examined the socioeconomic and natural driving forces in urbanization on the Mongolia Plateau, which is reflected in urban land and urban population changes, and investigated the impact on the urban environment. As the two most important cities in their respective country and region, Hohhot and Ulaanbaatar share the similar geophysical and cultural and historical context. Recent economic reforms in the Mongolian Plateau have significantly influenced both cities. A comparative analysis of urbanization and environmental changes of these cities can reveal useful insights for policy makers and urban planners in the region.

\section{Conceptual framework, research questions, and hypotheses}

Based on several fundamental concepts in urbanization and urban sustainability, we constructed a conceptual framework as a foundation to guide this research (Fig. 1). We conceptualized a city as a cultural landscape, including high population density and extensive impervious areas with different land use and land cover types, in which structure, functions, and dynamics are determined by coupled human-environment interactions (Pickett et al, 1997; Wu, 2010 \& 2014). Urbanization has been defined from both a demographic perspective and a land perspective. From a demographic perspective, urbanization is the increase in the ratio between urban population and the total population. From a land perspective, it refers to the expansion of the urban built-up area, implying the conversion from its previous state into an urban built-up area. Causes for urbanization can be classified into natural factors and socioeconomic factors. Natural factors (e.g., geographic locations, environmental conditions) have long been recognized as essential determinants of a city's location; especially in the historical period before the industrialization of a country (Fan et al., 2014). Socioeconomic factors, particularly in the industrial stage and at economic development levels, have played essential roles in urbanization. The tight connections between the urbanization ratio and the economic development level were highlighted by the seminal work of Davis (1965) and verified by others (e.g., Acemoglu et al., 2002). Empirical evidences also showed that urban land expansion was closely related to economic development, policy, and extreme events (Gong et al., 2013; Fan et al., 2014; Tian et al. 2014). Despite the plethora of literature on urbanization, the differences in spatiotemporal changes between western countries and urbanization in transitional economies, such as China 
and Mongolia, remain unclear. Most current research on urban sustainability is drawn from the experiences of cities from western countries (Portney 2003; Wheeler and Beatley, 2004), with a few exceptions (e.g., Rabionovitch and Leitman, 1996; Fan and Qi, 2010). Furthermore, are there differences in urbanization within the cities of transitional economies? What has caused all these differences? How has urbanization been linked with the characteristics of the cities, such as population size, location, and the level of economic development?

A key to analyzing driving factors of urbanization is to expand beyond the traditional, natural, and market factors and to include institutional factors unique to transitional economies and their enhancing global linkages. For example, China has experienced several institutional changes that may have had great influence on various aspects of urbanization. By relaxing the household registration system, which identifies a person as a resident of an area, the movement of the population may be directly affected. The installations of legal land and property markets may have altered demand for housing, thus influencing land use change and urban expansion. Fiscal decentralization may have provided incentives for local government to lease large amounts of land to boost their revenue. To what extent have institutional factors provided incentives for urbanization at local levels? In this paper, we assessed the impact of urbanization on urban ecosystems by measuring air quality and the levels of common air pollutants. Furthermore, we examined how human and natural systems have evolved in Ulaanbaatar and Hohhot as urbanization progressed.

Two theories exist to explain how urbanization can be linked to human and natural systems: the Environmental Kuznets Curve (EKC) and Urban Environment Transition (UET). The EKC argues that economic growth initially increases environmental burdens but, after a certain period, will reduce these environmental burdens (Stern, 2004); however, it only considers local environmental burdens for cities with advanced economic development levels, where most of the environmental burden may be transferred to other places through industrial relocations and emissions of greenhouse gases.

The UET, on the other hand, associates the environmental burdens of a city and its impact at local, regional, and global scales with its economic development level (McGranahan, 2001). It argues that poor cities, neighborhoods, homes and workplaces principally located in the Global South tend to create localized, immediate, and health-threatening environmental problems, such as diarrheal diseases and acute respiratory infections due to lack of sanitation and utility infrastructure. In contrast, affluent cities in industrialized countries generate global, environmental burdens lasting generations, such as high-level carbon emissions; occurring as more urban lifestyles increase resource consumption and generate more waste, yet take measures for protection or dispose environmentally hazardous waste elsewhere. According to UET, middle-income cities, such as industrial cities from transitional economies, will be somewhere in the middle range. They have a somewhat delayed citywide or regional environmental problems such as ambient air pollution or polluted waterways from industrial smoke, sulfur dioxide, and particulates. Overall, the urban environments in the industrial cities in transitional economies are worse than those in most cities in advanced countries (Zhou et al., 2007; Fan and Qi 2010). Nevertheless, we argue that a positive, institutional shift may occur when policymakers take a 
proactive approach, which may change the course of UET and make the city move toward urban sustainability.

We believe that the UET theory, complemented with EKC, will help us to develop a comprehensive picture and capture the environmental burdens of cities at different spatiotemporal scales. To explore the complex relationships between the human and natural systems, we therefore utilize EKC and UET as our theoretical foundation for analysis.

In this paper, we demonstrate how the conceptual framework described above can be used to analyze the urbanization, its driving forces, and its impacts on Ulaanbaatar and Hohhot. The specific research questions include:

(1) What are the spatio-temporal changes in the urban population, urban land expansion, and the urban environment in Hohhot and Ulaanbaatar?

(2) How has urbanization co-evolved with urban environmental change; and how have both been driven and constrained by both socioeconomic factors such as economic/industrial development and natural factors such as climate change and the inherent geophysical conditions of the region?

(3) How have globalization and institutional regulations/policies affected urbanization patterns and the urban environment in Hohhot and Ulaanbaatar, respectively?

We developed the following hypothesis for the above questions:

$\mathbf{H}_{1}$ : Although rapid urbanization has occurred in Hohhot and Ulaanbaatar since the launch of the economic liberalization, large variations exist in urban population, urban land expansion, and urban environmental change.

H2: Urbanization and the changes in urban ecosystems, reflected by measurements of air pollution, have direct connections with each other and are closely associated with natural factors and with the level of socioeconomic development that can be explained by UET and EKC.

$\mathbf{H}_{3}$ : Socioeconomic transformation reflected by increasing links with global communities and policy shifts have exerted a significant influence on urban expansion and sustainability thus there is possibility that the shape of the EKC curve may be altered, which may lead to an earlier decrease in environmental burdens.

\section{Study area, data, and methodology}

\subsection{Study area}

The Mongolia Plateau refers to a wide area of $\sim 2.6$ million $\mathrm{km}^{2}\left(37^{\circ} 46^{\prime}-53^{\circ} 08^{\prime} \mathrm{N}\right.$ and $87^{\circ} 40^{\prime}-$ $122^{\circ} 15^{\prime} \mathrm{E}$ ) in the center of the Central Asian Plateau (John et al., 2013). Greater Hinggan Mountains, Yin Mountains, Altai Mountains, and Sayan and Khentil mountains bounded the area in the east, south, west, and north, respectively. The vast extent of the plateau includes the regions of three administrative units: Mongolia, most of Inner Mongolia, and the Xinjiang 
Autonomous Regions in China; and additionally, part of Buryatia and the southern Irkutsk Oblast in Russia. In our study, we focus our discussion on a region composed of Mongolia and the Inner Mongolia Autonomous Region of China. Hohhot and Ulaanbaatar are the capitals of Inner Mongolia and Mongolia, respectively (Fig. 2).

Hohhot is located at the south-end of the plateau and Ulaanbaatar is located in the mid-northern

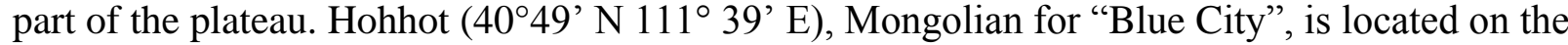
Tumuochuan Plain, the south-central part of Inner Mongolia, and is surrounded by the Yellow River, the Hetao Plateau to its south, and the Daqing Mountain to its north. Hohhot had a population of 2.87 million (1.98 million urban population) in 2010. With a cold, semi-arid climate, the city has a low annual average temperature of $6.7^{\circ} \mathrm{C}$ and an annual precipitation of $400 \mathrm{~mm}$. Falling within the mid-latitude, dry, semiarid steppe according to the Koeppens classification, Hohhot has long, cold and very dry winters and warm, somewhat humid summers, with strong winds especially in spring. Although Han Chinese people constitute the majority of the residents $(87.2 \%)$, Hohhot has a long and significant presence of ethnic minorities, including Mongolian (8.2\%), Hui (1.3\%) and Man (1\%). Founded by Mongol ruler Altan Khan in the late $16^{\text {th }}$ century, the city has a rich cultural background. As the region's administrative, economic, and cultural center, Hohhot has experienced fast population growth and economic development since the 1990s. Interestingly, the city is also nicknamed "the Dairy Capital of China", not only because of Mengniu and Yili, two prominent dairy producers, are headquartered in the city, but also because of Inner Mongolia's long history of providing milk and other related animal products based on its rich grasslands.

Ulaanbaatar $\left(47^{\circ} 55^{\prime} \mathrm{N} 106^{\circ} 55^{\prime} \mathrm{E}\right)$ means "Red Hero" in Mongolian. The city is located in the north-central part of Mongolia and in a valley on the Tuul River at the foot Bogd Khan Uul Mountain. Ulaanbaatar falls in the subarctic climate zone with cool summers and dry winters. Due to its high elevation, relatively high latitude, distance from any coast, and the effects of the Siberian anticyclone, Ulaanbaatar is the coldest national capital in the world. With a monsooninfluenced, cold, semi-arid climate, the city has long, cold and dry winters and brief, warm summers. The dominant ecosystems are the Mongolian-Manchurian temperate grasslands with $400 \mathrm{~m} \mathrm{yr}^{-1}$ of annual rainfall. The vegetation type is primarily meadow steppe that transitions to a forest steppe along an elevation gradient both north and south of the city. The Gorkhi Terelj national park is to the northeast of the city and includes tree species such as larch, spruce, pine, aspen, birch, and ash. As the capital of the country, Ulaanbaatar is the largest city in Mongolia, hosting a population of 1.4 million in 2013 - 47\% of Mongolia's total population and 69\% of the total urban population (National Statistical Office of Mongolia or NSOM, 2015). Apart from the political importance of Ulaanbaatar, the city contributes to a significant part of Mongolia's economic development. Two-thirds (65\%) of Mongolia's GDP was generated in Ulaanbaatar in 2013 (NSOM, 2015). Ulaanbaatar's urban development is concentrated along the Tuul River valley, with the city's core along the north side of the river, extending its built-up area of approximately $24 \mathrm{~km}$ along an east-west direction.

\subsection{Data and Methodology}


We used a multidisciplinary approach and relied on a variety of data sources to assess the changed urban landscape and the environment in Hohhot and Ulaanbaatar. We employed RS/GIS on satellite images for processing spatial land-use data and air pollution data, secondary statistical data from the respective bureaus of the local/national governments, as well as qualitative data from first-hand observations and interviews with local experts, etc.

\section{Urban land data and processing}

To assess urban expansion, we used urban built-up land and associated characteristics as indices of urbanization. We derived the urban built-up land of Ulaanbaatar and Hohhot for the 19902010 period from the Landsat 5 Thematic Mapper. All level 1G Landsat images, downloaded from the USGS website, were geometrically corrected to the UTM coordinate system. We downloaded the administrative boundary datasets of China and Mongolia from the geographical information center of China and the GADM organization (http://gadm.org), respectively. Urban built-up land was extracted by using an integrated approach combining supervised classification, unsupervised classification, and visual interpretation. Erdas Imagine 9.3 was used to complete the classification and post-classification enhancements. We conducted an accuracy assessment for the 2010 urban land maps, based on Google Earth high-resolution images. We consider our classification sufficiently accurate with kappa coefficients of 0.88 for Hohhot and 0.90 for Ulaanbaatar. Based on this land-use data, we then used a set of urban growth indicators (Fan et al., 2012; Schneider and Woodcock, 2008) to assess the degree of urban expansion and its relationship to the urban population: (1) growth of urban land, (2) urban population density in urban land, and (3) the ratio of population growth to urban land growth.

\section{Environmental data and processing}

For the environmental quality, we collected air pollution data of particulate matter (PM), $\mathrm{SO}_{2}$, and $\mathrm{NO}_{2}$ from 2003 through 2013. In addition to the annual data obtained through the statistical yearbooks of Hohhot and Ulaanbaatar, we also processed the air quality data by ourselves based on satellite imageries. We obtained $\mathrm{SO}_{2}, \mathrm{NO}_{2}$, and aerosol optical thickness (AOT) products at $0.25 \times 0.25$ degrees resolution from the Ozone Mapping Instrument (OMI) on the Aura Satellite by using the simple subset wizard portal (http://disc.sci.gsfc.nasa.gov/SSW/\#keywords=). We accessed OMSO2e or daily total column $\mathrm{SO}_{2}$ in Dobson units $\left(1 \mathrm{DU}=2.69 * 10^{16}\right.$ molecules $\mathrm{cm}^{-}$ ${ }^{2}$ ). In addition, we downloaded OMNO2d, which is the daily Cloud-Screened total and tropospheric Column $\mathrm{NO}_{2}$ (molecules $\mathrm{cm}^{-2}$ ). We also obtained AOT from the multi-wavelength, aerosol optical thickness (0-1, unitless), OMAEROe product at $342 \mathrm{~nm}$ and $483 \mathrm{~nm}$ using the Giovanni online tool (http://disc.sci.gsfc.nasa.gov/giovanni). We processed the data into monthly, seasonal, and annual composites in order to reduce uncertainty and OMI data artifacts. In addition, we obtained PM2.5 $\left(\mu \mathrm{g} / \mathrm{m}^{3}\right)$ from our local collaborator in Ulaanbaatar. The data was measured at the Institute of Meteorology, Hydrology and Environment in the center of the city using a nephelometer.

We obtained EVI2 from the new Vegetation Index and Phenology (VIP) dataset of the NASA MEaSUREs (Making Earth System Data Records for Use in Research Environments) program (http://vip.arizona.edu/viplab_data_explorer.php\#). The VIP dataset spans three decades (19812010) of consistent EVI2 and NDVI derived from both AVHRR and MODIS, with a resolution 
of $5.6 \mathrm{~km}\left(0.05^{\circ}\right)($ Jiang et al, 2008). In addition, we also download NDVI3g, the third generation of GIMMS NDVI for 1981-2010. We derived summer mean composites from June, July, and August (JJA) as well as the growing season maximum (April-October). Similarly we obtained climate drivers from the MERRA datasets to match the satellite VI record composites. The $0.5^{\circ} \times 0.5^{\circ}$ resolution, MERRA monthly mean total precipitation $\left(\mathrm{mm} \mathrm{yr}^{-1}\right)$ data (PRECTOT) data, and the temperature of $2 \mathrm{~m}\left(\mathrm{~T} 2 \mathrm{M},{ }^{\circ} \mathrm{C}\right)$ were obtained from the tavg1_2d_flx_Nx dataset and tavgM_2d_slv_Nx, respectively, using the simple subset wizard on the Goddard space center website (http://disc.sci.gsfc.nasa.gov/SSW/). In addition, we also obtained an independent precipitation record from the Climate Research Unit 3.21's monthly climate data record from 1981 through 2012. (http://catalogue.ceda.ac.uk/uuid/ac4ecbd554d0dd52a9b575d9666dc42d). We derived summer (JJA) and winter (DJF) mean temperatures as well as summer and annual accumulated precipitation. Based on the data from ground observations of Ulaanbaatar from 2004 to 2014, we also compiled the data of $\mathrm{PM}_{2.5}$ by using annual mean, the mean of the three coldest months, and the monthly mean.

\section{Socioeconomic and population data and processing}

To understand the socioeconomic driving forces of urbanization, we collected widely accepted indicators in: (1) economic development of the cities and their respective region/country, such as GDP, GDP per capita (GDPpc), percentages of primary, secondary, and tertiary industries of GDP, and foreign investment, (2) population of the cities and their respective region/country, such as total, urban, and migrant population. The major sources of the data are from the statistical yearbooks of Hohhot (2002-2012), Inner Mongolia (2003-2013), and China (20032014), as well as from the Mongolia National Statistical Bureau (Mongolia UB source http://www.1212.mn/en/). To understand the natural driving force of urbanization, we also collected the climate data of the region and relied on the primary data generated by our research group on the changing grassland area and grassland productivity, and the population and livelihood of herdsman in Mongolia and Inner Mongolia.

We conducted first-hand data collection on site while visiting different parts of the urban areas of Ulaanbaatar and Hohhot, organizing workshops, and interviewing local experts such as academic scholars, public decision makers, business owners, as well as representatives of urban and rural residents. All these activities have provided us a much richer and deeper understanding of the local context of urbanization and how that has affected people's daily life as well as what the most concerning issues are to decision makers and residents.

Based on the data processed from these three aspects, we analyzed urbanization, changes in urban environmental quality, and the relationship between urban growth and economic development. We first mapped the urban land expansion and compared the speed and pattern of urbanization in 1990-2010 from both urban land and population growth perspectives. With the processed environmental data, we graphed air pollution indicators for Hohhot and Ulaanbaatar in the 2000s. We used a correlation matrix and trend line plots to further reveal the co-evolved and complex relationships between urbanization, economic development, and environmental quality and then identified certain factors that are of particularly significant impacts on urbanization and 
air quality. We finally placed our results within our conceptual framework (Fig. 1), especially the EKC and UET concepts.

\section{Results}

\subsection{Urbanization and urban land expansion}

Hohhot increased its urbanized area from $89 \mathrm{~km}^{2}$ in 1990 to $117 \mathrm{~km}^{2}$ in 2000 , but then almost doubled its size to $229 \mathrm{~km}^{2}$ in 2010 , making an annual area increase of $\sim 10 \mathrm{~km}^{2}$ /year for 2000 2010 (Fig. 2). While development occurred mostly along the north and south urban fringe area from 1990 to 2000, urban built-up lands were added to the rest of the urban periphery area at a much faster rate from 2000 to 2010 . While many of the newly growing urban land can be categorized as edge growth (i.e., the land added to the edge of an existing urban land), many patches of land are leapfrog-like (e.g., the newly converted urban land is not connected or adjacent to existing urban land areas). These appeared mostly to the north and south of Hohhot's urban core.

Although Ulaanbaatar fell behind Hohhot in overall urbanization rates and in the speed of urban expansion, it nevertheless expanded noticeably from $82 \mathrm{~km}^{2}$ in 1990 to $142 \mathrm{~km}^{2}$ in 2010 , particularly after 2000 (Fig. 2). While examining high-resolution imagery from Google Earth and observations from our field research trip in the summer of 2014, we found that the settlements in the northern hilly areas accounted for most of Ulaanbaatar's urban expansion. However, during our field trip in the summer of 2014, we also witnessed that a significant portion of urban expansion had also occurred to the southern part of the city, which was not captured by the satellite image from 2010. Urban development has passed beyond the Tuul River as new highrise condominium buildings, shopping malls, and Ger settlements are now being set up in a traditionally preserved area.

\section{Speed and characteristics of urbanization}

Urbanization has unfolded at an unprecedented rate for these two important cities on the Mongolia Plateau (Fig. $2 \& 3$ ), as reflected by the increase in the urban population and the expansion of urban built-up land. Although both cities have increased their urban population by over 100\% from 1990 to 2010, Ulaanbaatar remained behind Hohhot with its population of 0.55 million and 1.15 million in 1990 and 2010, respectively, whereas Hohhot had 0.81 million and 1.80 million in 1990 and 2010, respectively. Both cities started with similar amounts of urban built-up land, with $89 \mathrm{~km}^{2}$ in Hohhot and $82 \mathrm{~km}^{2}$ in Ulaanbaatar; however, Hohhot expanded much faster with $229 \mathrm{~km}^{2}$ of urban built-up land in $2010-61 \%$ more than Ulaanbaatar (142 $\mathrm{km}^{2}$ ). Overall, Ulaanbaatar lagged behind Hohhot for about a decade in terms of the amount of urban population and urban built-up land. For example, in 2000, with a population of 0.76 million and $94 \mathrm{~km}^{2}$ of urban land, Ulaanbaatar reached a level of urban population ( 0.81 million) and urban land $\left(89 \mathrm{~km}^{2}\right)$ similar to Hohhot in 1990 (Fig. 3).

It is also interesting to examine the dynamic of urban population growth vs. urban land expansion. For Hohhot, the urban population density grew from 9108 people $/ \mathrm{km}^{2}$ in 1990 to 9611 people $/ \mathrm{km}^{2}$ in 2000 , but then dropped to 7842 people $/ \mathrm{km}^{2}$ in 2010 . This indicates that 
urban population growth outpaced the urban land growth in the first decade but it had interchanged in the second decade, i.e., urban land growth outpaced urban population growth. In contrast, Ulaanbaatar's urban population growth always outpaced urban land expansion, leading to a continuous increase in urban land density from 6719 person $/ \mathrm{km}^{2}$ in 1990 to 8104 person $/ \mathrm{km}^{2}$ in 2000 and to 8111 person $/ \mathrm{km}^{2}$ in 2010 .

\subsection{Changes in urban environmental quality}

Both cities have experienced environmental impact brought on by the urban transformation that unfolded within the city boundaries, with neither clearly improving some air pollutant indicators while other indicators show worse values over time. While Hohhot seems to have had worse air pollution than Ulaanbaatar in the early 2000s - since Ulaanbaatar had better values in every measure from $\mathrm{SO}_{2}, \mathrm{NO}_{2}$, and aerosol concentrations of size $483 \mathrm{~nm}$ and $342 \mathrm{~nm}$ - the gap between the two cities became smaller (Fig. 4). Indications from $\mathrm{NO}_{2}$ and $\mathrm{SO}_{2}$ show that Ulaanbaatar's overall air quality became worse than Hohhot's. As Hohhot's decreased from or oscillated some constant values $\left(0.04-0.06 \mathrm{mg} / \mathrm{m}^{3}\right)$ over a time period, Ulaanbaatar's concentrations for these two pollutants have continually increased. Indeed, Hohhot's overall air quality, measured by the percentage of days equal to or better than the Grade II level ${ }^{1}$, indicates that the air quality of the city experienced gradual improvement during the period of 2003-2012, but dramatically worsened from 2012 to 2013. Further, the main determinant to the overall trend of air quality in Hohhot was the $\mathrm{PM}_{10}$ level, which first decreased gradually from $116 \mathrm{ug} / \mathrm{m}^{3} \mathrm{in}$ 2003 to a low $68 \mathrm{ug} / \mathrm{m}^{3}$ in 2010 and then increased rapidly to a high of 146 in $2013 \mathrm{ug} / \mathrm{m}^{3}$, more than double the value in 2010 .

Our research cautions us that annual data tends to hide valuable information about the seasonal variations during the year as well as the values for the extreme pollution period (Fig. 5). One can see that while annual mean presented one picture, the mean of the three coldest months, December, January, and February (DJF), presented a quite different picture. The annual mean shows a flat trend with slight elevated values (100 110) of PM2.5 in 2009 and 2013, whereas the DJF mean shows two substantially high values (200 230) of $\mathrm{PM}_{2.5}$ in DJF of 2007 and 2014. The monthly mean data shows greater oscillation of PM 2.5 and three spikes (310 320) in January 2008, May 2009, and March 2013. Therefore, we consider using the annual data only as a reference and to derive the general trend.

\subsection{Urban growth and economic development}

Population growth of Hohhot and Ulaanbaatar followed their economic development (i.e., GDPpc) (Fig. 6). In particular, urban population can be modeled well with a logarithmic function of GDPpc; i.e. urban population grew very fast when GDPpc grew slow initially, but as GDPpc continued to grow, urban population seemed to stabilize and grow little. Overall, our findings imply the strong correlation between economic development and urban population growth.

\footnotetext{
1 The Chinese government calculated the air pollution index of cities based on the concentration of $\mathrm{SO}_{2}, \mathrm{NO}_{2}$, and $\mathrm{PM}_{10}$. A city's air quality then can be evaluated into one of the five grades based on the value of the air pollution index. While Grades I and II refer to excellent and fine air quality, Grades III, IV, V represent a light, medium, and heavy degree of air pollution.
} 
Further analysis on the economic structure of these cities revealed that Hohhot and Ulaanbaatar have experienced significant economic restructuring towards a service-oriented economy (Fig. 7). With 54\% and $43 \%$ of GDP coming from the tertiary sector for Hohhot and Ulaanbaatar, respectively, the tertiary sector has dominated, surpassing the secondary sector that is composed of manufacturing, construction, and mining. While Hohhot has mainly seen growth in its manufacturing sector, followed by construction and primary sectors, Ulaanbaatar has witnessed major development in mining, primary, manufacturing, and construction sectors, in decreasing order. It is worth mentioning that with a $25 \%$ contribution to Ulaanbaatar's GDP in 2013, mining is a highly distinguished sector in Ulaanbaatar's economy, which is consistent with the mining frenzy by the foreign investors in Mongolia since the 1990s. The compositions of the tertiary sector implies that both cities have increased their proportions for producer services during the periods, such as real estate and financial services, from 6\% in 2003 to $8 \%$ in 2011 in Hohhot and $6 \%$ in 2000 to $12 \%$ in 2013 in Ulaanbaatar. This indicates that a gradual transition towards a post-industrial economy is occurring for both cities.

\section{Discussion}

Both cities have experienced fast urban expansions, driven by its rapid economic development and restructuring. The impact of urbanization and development are obvious not only by the direct transformation of the landscape from non-urban to urban land, but also by the severe degradation of the urban environment, indicated by the air quality indexes such as $\mathrm{SO}_{2}, \mathrm{NO}_{2}$, AOT342, AOT483, $\mathrm{PM}_{10}$, and $\mathrm{PM}_{2.5}$. However, they have also experienced differences in temporal patterns, the magnitude of change, and the causes in following aspects.

\subsection{Urbanization, environmental change, and economic development}

The three important aspects highlighted in our research of Hohhot and Ulaanbaatar (i.e., urbanization, economic development, and environmental change) have co-evolved over time with complex interactions (Fig. 8). For Hohhot, the concentrations of air pollutants initially increased and then decreased as GDPpc increased. This dynamic can be partly explained by the EKC concept. However, it should be noted that policies made at the local level and beyond, including those from the central government, have critically affected the air quality in Hohhot. In 2002, the State Council announced the "Plan for Prevention and Control of Atmospheric Pollution for Focused Cities" for 113 major cities, including Hohhot. The State Council required these cities to reach China's national air quality standard by 2005 by taking a series of necessary measurements such as adjusting their energy structure, implementing clean production, reducing car emission, etc. Hohhot municipal government implemented the plan and made substantial progress. For example, from 2002 to 2007, the city removed 100,000 small smoke stacks in the four central city districts and another 200,000 smoke stacks mainly in urban-rural fringe areas, significantly reducing soot pollution. As a result, Hohhot was ranked as one of the top four cities in terms of air quality out of 15 provincial capital cities in Northern China from 2004 to 2006. Furthermore, as high quality coals were required to be used in rural counties, the great metropolitan area air quality of Hohhot in the 2000s significantly improved from that of the 1990s. For Ulaanbaatar, it seems that the city has not reached a similar tipping point to reduce the pollution level. Surprisingly, urban population did not seem to have a clear relationship with urban pollution. In Hohhot, air quality is improving with urban population growth after its initial 
low (e.g. $\mathrm{NO}_{2}$ and $\mathrm{SO}_{2}$ ); whereas for Ulaanbaatar, almost all measures of air pollutants generally increased their concentrations with population growth, which means a degrading air quality. This indicates that a larger population does not necessarily result in a lower air quality.

\subsection{Natural and socioeconomic factors}

\section{Physical influences}

Biophysical and climate factors, such as green coverage, temperature, or precipitation, may affect air pollution. Green coverage of a city has always shown a negative correlation with air pollution and albedo (Chen, 2015b). Research also shows that urban tree cover has the ability to significantly reduce air pollution either by uptake through leaf stomata or through interception in the case of particulate matter (Novak et al., 2006). Intercepted particulate matter is then either washed away by rain or drops to the ground with leaf/twig fall. Studies found that temperature played an indirect role in air pollution. $\mathrm{SO}_{2}$ and $\mathrm{NO}_{2}$ concentrations were significantly higher in the cold season owing to an increase in heating demand (Huang et al., 2013). On the other hand, an increase in $\mathrm{SO}_{2}$ and $\mathrm{NO}_{2}$ in summer came from an increase in vehicular traffic (Huang et al., 2013). Research has shown that areas with Ger housing during the winter months (DecemberFebruary) have 50\% more $\mathrm{PM}_{2.5}$ than the annual average (Guttikonda et al., 2013). As $60 \%$ of coal consumption in Ulaanbaatar is during the winter months, we expect to see a significant impact of cold temperature on air pollution in Ulaanbaatar. Although precipitation is generally considered to lower air pollution level, the actual relationship between air pollution and precipitation is very complex. While some studies reported that air pollution in the form of aerosols is conducive to the formation of droplets leading to rainfall, other studies suggest that there was a significant decrease in orographic rainfall with increasing aerosols and particulate matter concentrations (Guo et al., 2014).

We examined different variables, their correlations (Table 1), and their relationships with various pollutants (Fig. 9). Surprisingly, there seemed a lack of strong, significant correlations between the changes in physical variables and the concentration levels of air pollutants. It appears that the regression may have a misspecification problem, i.e., missing explanatory variables. This is one of the limitations of the current research. However, some factors seem to be highly significant. In Hohhot, for example, we found inverse relationships between metrics of annual precipitation as well as between summer means and growing season maximums of vegetation indices (EVI2 and NDVI) with pollutant concentrations. We also found a similar inverse relationship in Ulaanbaatar between annual precipitation and green cover (vegetation indices) with air pollutants $\left(\mathrm{SO}_{2}, \mathrm{NO}_{2}\right.$, and aerosols). For example, $\mathrm{NO}_{2}$ concentrations in Hohhot were highly correlated with JJA precipitation, whereas $\mathrm{NO}_{2}$ levels in Ulaanbaatar were negatively correlated with growing season greenness. For $\mathrm{SO}_{2}$, the growing season greenness (i.e., max NDVI mean) seems to be closely relevant to decreasing $\mathrm{SO}_{2}$ concentrations in both Hohhot and Ulaanbaatar. Not surprisingly, AOT levels in Ulaanbaatar were negatively correlated with summer precipitation (JJA), while PM $\mathrm{PM}_{10}$ for Hohhot showed no significant relationship to precipitation or temperature. Winter air temperature in Ulaanbaatar showed a close association with winter $\mathrm{PM}_{2.5}$ measurements. Ulaanbaatar's rapid increase in population and GDP was positively correlated with concomitant increase in air pollutants like $\mathrm{SO}_{2}, \mathrm{NO}_{2}, \mathrm{AOT}$, and $\mathrm{PM}_{2.5}$. We found an 
interesting, but unexpected, correlation between the Palmer's Drought Severity Index (PDSI) and $\mathrm{PM}_{2.5}$ in Ulaanbaatar. However, this could be explained by the rapid increase in the urban population during the combined drought- $d z u d s$ (extreme winters) of 2000-2002, when herding families moved to the capital following record livestock mortality rates of $30 \%$ (Sankey et al., 2009). In Hohhot, however, the increase of population and GDP was only positively correlated with $\mathrm{SO}_{2}$ and $\mathrm{NO}_{2}$.

In terms of topography, the Daqing Shan, or the "great blue mountains", to the north, and the Hetao plateau to the south bound Hohhot; they play a role in air quality. The name refers to the bend or meander of the Yellow River and it includes the fertile Hetao irrigation district. Unlike Ulaanbaatar, where the air pollution is compounded by high relief around the city, the negligible relief south of Hohhot possibly explains the relatively lower levels of PM10. The city has highly varying precipitation which has consequences to air pollution attenuation. $\mathrm{PM}_{10}$ in winter is in

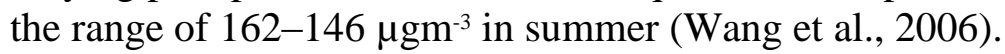

The mountains surrounding Ulaanbaatar constrict the dispersion of pollutants and thus local relief plays an important role in increased pollution levels (Guttikunda et al., 2013). The fact that Ulaanbaatar is the coldest national capital in the world certainly contributes to its needs for heating in winter. However, the heavy reliance on coal for its heating aggravates air pollution in winter. Due to data limitation, we are unable to examine the energy composition; but other research has indicated that the main reasons for its air pollution include increased heating from out-of-date coal burning power plants, boilers, and in situ coal/wood domestic heating and cooking which increase total emissions as well as lower mixing level heights $(<200 \mathrm{~m})$ (Guttikunda et al., 2013). It has also been reported that $\mathrm{SO}_{2}$ concentrations were significantly higher than normal during 1996-2009 (Luvsan et al., 2012). But, more importantly, Ulaanbaatar's $\mathrm{PM}_{2.5}$ level is alarmingly high. Its annual average $\mathrm{PM}_{2.5}$ in 2010-2011 was in the range of $136 \pm 134 \mu \mathrm{gm}^{-3}$ whereas the World Health Organization (WHO) guideline is $10 \mu \mathrm{gm}^{-}$ ${ }^{3}$ (Guttikunda et al., 2013). PM 2.5 in Ulaanbaatar's winter can be as high as $750 \mu \mathrm{gm}^{-3}$ (Davy et al., 2011).

\section{Institutional and social influences}

What distinguished Hohhot and Ulaanbaatar from other cities in developing economies are perhaps their transitional characters (Chen et al, 2015a). They have embraced the influences from both the newly developed market economy, including the global force, and the visible hand of the state policies at various spatial scales. Overall, the economic reforms of China and Mongolia have set the tone for economic development and population dynamics for both cities. Both cities started to gradually increase their economic performance, measured by GDPpc and population, after the economic reform launched in their respective countries (i.e., 1978 in China and 1990 in Mongolia), with a steady flow of migrant population to both cities (Fig. 10). Nevertheless, it was the national government's regional development policy for China's West and the globalization force to integrate Mongolia into the world economy, especially by joining the World Trade Organization (WTO) and the investment in its mining sector, that really launched the economy of Hohhot in 2000 and for Ulaanbaatar in mid-2000s (Chen et al, 2015b). 
Hohhot's fast urban expansion has to be considered in the context of China's national development policy (Chen et al, 2015a). It should be noted that China's urbanization significantly increased since the economic reform in 1978. However, just as the fast economic development first appeared mostly in China's east coast, a similar situation occurred in urbanization. Cities and towns grew rapidly in China's east coast as they received most of the nation's rural-urban migration, whereas cities in China's west, including Hohhot, retained their slow urbanization speed until the new millennium. China launched the West China Development Program (WCDP) in 2000, which had a significant influence on the development of cities in China's West (Fan et al., 2013). One of the central goals of the WCDP was to decrease the inequality of regional development, as the first two decades of China's economic reform mainly benefited east-coast areas while the western region fell even further behind the national average, with a GDPpc at $40 \%$ less than the average level of the eastern region. Although Hohhot fared quite well compared to other cities in China's West, WCDP nevertheless has further boosted the city's economic performance. For instance, before the WCDP, Hohhot's GDPpc grew at 17\% and $21 \%$ annually for periods $1978-1990$ and 1990-2000, respectively. These were not small achievements at all. However, after the WCDP, the city's economy further expanded, making its GDPpc grow at an even higher rate of 23\% from 2000 to 2010. At the beginning of WCDP, Hohhot was listed as No. 32 out of the 35 major cities ${ }^{2}$ in China in 2001, when measured by GDP per capita. In 2012, it significantly improved its ranking as it was listed as No. 11 out of the same 35 major cities.

Accompanying the takeoff of the economy were dramatic increases in urban population and urban land expansion at annual rates of $4.8 \%$ and $7.0 \%$ during the period of $2000-2010$ vs. $3.3 \%$ and $2.7 \%$ for the period of 1990-2000 for Hohhot. Economic development zones such as Ruyi, Jinchuan, and Jinhe, have been set up during our study period and have made substantial contributions to urban land expansion. In fact, economic development zones established during 1990-2010 account for a significant increase of urban expansion in Hohhot, not to mention residential development to accommodate workers from these economic development zones. Another major development is university campuses, which are also prevalent in other major cities in China. For instance, the university town of Hohhot started building in 2007 in a village called Luojiayin, $10 \mathrm{~km}$ east of the city proper of Hohhot, but in 2012, it already hosted six relocated universities and colleges with 100,000 students and faculty. This urban expansion pattern is not unique in Hohhot, as we have found similar patterns of urban expansion in studies of other cities in China, such as Hangzhou (Liu et al., 2011), Shanghai (Yue et al., 2010), and Chongqing.

Ulaanbaatar, as the national capital, is a reflection of Mongolia. The fact that Mongolia has huge deposits of copper, coal, and gold has increased optimism that it can develop like other resourcerich countries such as those in the Middle East. The dependence on its mining sector, which directly contributed to $25 \%$ of Ulaanbaatar's GDP (or $22 \%$ of Mongolia's GDP) has invited criticism as it has drained the labor and investment in other non-mining sectors, making

\footnotetext{
${ }^{2}$ These 35 major cities include 30 provincial capitals, except Lhasa, and five municipalities with independent planning status, i.e., the cities directly report their revenue to the central government, not their respective provinces. The five municipalities with independent planning status are: Dalian, Ningbo, Qingdao, Shenzhen, and Xiamen.
} 
Mongolia's economic structure too mining-dependent and extremely vulnerable to international markets of natural resources. In fact, the dip of GDPpc in 2009 may be related to the drop in global demand for Mongolia's mining exports due to the World Financial Crisis in 2008. Both Ulaanbaatar and Mongolia are confronted with the challenge to strategize investments in natural resources and to upgrade industry in other sectors.

Ulaanbaatar's urban development and environmental conditions have been significantly shaped by institutional factors. Compared to the 1978 urbanization ratio in China of 18\%, Mongolia had a much higher urbanization ratio of $52 \%$ in 1980 before its launch of economic reform in the 1990s. The political change in 1990 promoted the market economy and completely changed the urban development process in Mongolia, boosting its urbanization ratio to $70 \%$ in 2013 . While before 1990, urban development in Ulaanbaatar as well as other Mongolian cities were entirely planned, owned, and controlled by the government, after 1990, many developments occurred without any control and the private sector became significantly involved; this lead to both urban expansion and urban internal spatial transformation. The main changes include: the increased commercialization of the city's center and inner city region, the urban expansion in formal and informal Ger areas, the formation of satellite towns around Ulaanbaatar, and the increased suburbanization featuring single family houses (Badamdori, 2004; Amarsaikhan et al., 2011). As others have pointed out, urban transformation in Ulaanbaatar, or Mongolia at large, are driven by four major political, socio, and economical changes (Chinbat et al., 2006). First, like any transitional economy, the country had moved from a central planning economy towards a private market economy, starting in 1990, which led to the next three major changes of the society. Second, in the economic sphere, many state industrial plants had been closed down and private commercial and service companies had been set up, resulting in the consequent urban land-use changes. The third and fourth major changes that have had a huge impact on the population dynamics of the city and the dimension of social equity are the change of migration policies and the rise of income differences, which further aggravated the spatial differentiation of the urban spaces (Chinbat et al., 2006). In particular, the expansion of Ger areas, appearing after 1990, have become a major consequence of Ulaanbaatar's urbanization, housing $58 \%$ of its urban residents and occupying 70\% of the geographic area of Ulaanbaatar (Amarsaikhan et al., 2011; Amarbayasgalan, 2008). Our results concerning the urban expansion of Ulaanbaatar coincides with the findings of Amarsaikhan (2011) that the newly-added urban built-up areas were concentrated in the original agricultural lands along the Tuul River and in the mountainous areas in the north, within the traditional Ger areas. Furthermore, satellite towns emerged in response to the high land prices in the city center (Amarsaikhan, 2011).

It should be noted that the migration policies had direct impact on population dynamics in both Hohhot and Ulaanbaatar, and in particular the expansion of the Ger area in Ulaanbaatar. Until the early 1980s, rural-urban migration was under strict control in China and Mongolia. However, the new constitution from 1992 gave people rights to free circulation and settlements in Mongolia. This not only unleashed a sudden and great immigration flow to Ulaanbaatar in the 1990s, but continued and further elevated in the following decade, increasing Ulaanbaatar's population by 39\% and 52\%, respectively, for the periods of 1990-2000 and 2000-2010. In particular, the extremely cold winters in 1999-2001 made the livelihood of rural herder 
households extremely harsh. A large portion of livestock was lost, which triggered a massive migration to Ulaanbaatar in the following decade (Chen et al., 2015a). The city was underprepared for this inflow; most rural-urban migrants settled in the urban fringed area, with little infrastructure including heating, potable water, sewage, solid waste collection, and public transit. The migrants built traditional round tents, which were custom in their herdsman life style, but had no intention to move these tents. From an aerial view, we witnessed a massive extent of the Gers in and around parts of Ulaanbaatar, a rather unique phenomenon for any periurbanization in a developing country. Ger areas have become a major source of urban environmental pollution and de facto slums (Herro et al., 2003; ADB, 2008; Guttikunda, 2007). Municipal and national governments as well as international organizations such as the World Bank, the International Monetary Fund, and the Asian Development Bank, etc., are now concerned and seek effective policies to accommodate the rural-urban migrants and provide services to the Ger areas.

Although Hohhot also experienced the same rural-urban migration flow due to the relaxation of population control in China, the scale and magnitude is not comparable to that of Ulaanbaatar. We argue that because Ulaanbaatar is the primate city, a leading city in its country or region that is disproportionally larger and more prominent in any aspect from any other cities, in Mongolia, it makes Ulaanbaatar the most popular place for rural-urban migration, similar to other capital cities in Southeast Asian and African economies such as Phnom Penh, Manila, Jakarta, and Lagos. Hohhot, however, is a provincial capital and shares the rural-urban migrant flow with two other major cities of similar size, Baotou and Erlianhot, located within the autonomous region, and with other major cities outside of Inner Mongolia.

Moreover, the urban development of these two cities should also be examined through a social lens, such as social equity and cultural heritage. In both cities, increasing disparity between the haves and have-nots, especially between the newly rising urban middle- and upper-classes and the Ger residents or low-income rural migrants, calls for policies addressing these severe issues that can hinder the sustainable development of both cities. Policy makers pay attention to the unique historic, ethnic, and cultural characteristics of their cities for urban sustainability. For instance, Hohhot is a provincial capital of an ethnic autonomous region with high concentrations of ethnic minorities and is comprised of 8.2\% Mongolian, 1.3\% Hui, and 1\% Man, etc., in 2011. Unlike some other cities, such as Urumqi, Hohhot has had a long harmonious ethnic relationship between Han, Mongol, Islamic, and Man since 1500 (Wang, 1997). The arrangement followed a hybrid spatial structure with different ethnicities living together throughout the cities, but some blocks congregated a large percentage of minority ethnic groups, such as Tongdao Road in the Huimin District. Nevertheless, incidences in other cities in China's Northwest, such as Urumqi in 2009, only emphasize that effectively-built harmonious ethnic relationships in an ethnic autonomous region - through a combination of economic development, migration strategy, and policy incentives - will be critical to the urban sustainability of Hohhot.

\subsection{Reflection on the conceptual framework}

EKC and UET appeared partially effective in explaining the relationship between economic development, environmental quality, and major environmental burdens of industrializing cities in 
transitional economies. Two reasons hinder the applications of EKC and UET for our study cities. First, we only examined how GDPpc and population size may be related to air quality. Although GDPpc and population size are considered as the major causes of air pollution for a city, it is too simplistic to include just these factors. Despite being a widely accepted indicator for economic development, GDPpc did not reveal whether the economic structure, such as composition of industrial sectors, may greatly influence the air quality of the city. The composition of industries, for example, is as important as the GDP value. Other factors such as urban construction activities, the total number of automobiles, traffic controls, and coal used for heating and cooking, etc. can also be responsible for the pollution. Similarly, population size did not provide information on the population's energy composition profiles, as well as urban settlement and transportation patterns, which have also been highlighted as important factors for air pollution. Second, the ambient air pollution data does not have a clear trend, such as increasing air quality or decreasing air quality, for both cities. This makes it difficult to use both EKC and UET for explanations since they rely on clear trends of environmental burdens.

According to UET, Hohhot and Ulaanbaatar will be classified as industrial cities in transitional economies that have typical environmental burdens from ambient air pollution. However, due to the rapid economic growth and the consequential increase in income disparity, we argue that both cities have also displayed environmental burdens seen in other city categories of UET, such as carbon emissions from affluent cities in industrialized countries and health-threatening environmental problems seen in poor cities in the Global South. For instance, both cities now have suburb areas with single detached houses and gates, a typical sprawling urban landscape in western countries. This is also where carbon emissions and ecological footprints are much higher than the cities per capita value due to a heavy reliance on auto transportation and to a life style with a high level of material consumption-both which contribute to global climate change. At the other extreme, both cities have dilapidated areas where basic city services, such as water supply, utilities, sanitation, and garbage collection are not offered. This is especially seen in Ger areas in Ulaanbaatar and in urban periphery areas for migrant workers in Hohhot, which are similar to the mega cities from the most underdeveloped countries in Sub-Sahara Africa. In sum, fast urbanization and increasing disparity have made both cities embrace all kinds of environmental burdens from different city categories in UET.

The urban environment in Hohhot and Ulaanbaatar are worse than most cities in advanced countries (Zhou et al., 2007; Fan and Qi 2010), as indicated by air quality measures in this paper. Our interviews with local policy makers, scholars, and residents highlighted that air and water pollution are currently the biggest concerns of the local governments and residents. As EKC and UET have not considered any institutional intervention, we argue that if policy makers take a proactive approach rather than leaving everything in the hands of the market, this may alter the urban environmental trajectory towards urban sustainability. For example, as urban land expansion continued, the Hohhot government deployed regulations to promote reforestation around the city. As a result, the city has seen a significant increase of forestland between 2000 and 2004, albeit at a cost of its agricultural and grazing land (Huang et al., 2008). In future research, it is worthwhile to examine in detail how government incentives, policies, and regulations may have had a significant impact on urban environment. 
The key lessons on urbanization from this study include the following: First, while economic development serves as an essential driver for urban growth, its impact on urbanization seems to decrease over time. Second, the urbanization of transitional economies exemplified by these two cities are driven by the pull from the development by both manufacturing and tertiary sectors and by the push from the change in the primary sector. This is different from either developed countries whose urbanization was mainly pulled by industrialization or from low-income, developing countries whose urbanization was pushed by poverty in rural areas. Third, the increasing integration with the global economy in the recent decade and the institutional force, despite the transition from central planning to the market paradigm, have stood out remarkably as key determinants for urbanization.

This paper only focuses on air pollution indicators, which have more local and short-term spatial and temporal scales. It did not discuss other environmental impacts beyond the city's boundary such as carbon emission, which is an environmental burden on the global community that should be considered as an important part of the environmental impact of urbanization. For example, we also did not discuss how urbanization is related to rural-urban migration or how it may be triggered by ecological migration due to the overall degradation of grassland. These limitations stress that studies of cities cannot be isolated within their geographic boundaries but instead must be connected with studies of the large natural and socio-economic systems, which require collaboration between scientists from multiple disciplines. Nevertheless, as two of the most important cities in the Mongolia Plateau, lessons from Hohhot and Ulaanbaatar from this paper still yield useful insights for policy makers on urban planning and environmental management.

\section{Conclusions}

We compared Hohhot and Ulaanbaatar to find the changes and the underlying driving mechanisms that occurred during a rapid urbanization era on the Mongolia Plateau by focusing on change in the landscape and population and its impact on the urban environment. We used a multidisciplinary approach and multiple data sources to assess the relationships between the landscapes and the environment. We found a rapid urbanization of Hohhot and Ulaanbaatar based on population growth and land expansion from 1990 through 2010, with a much faster rate in 2000-2010. While the level of economic development is closely associated with urban expansion, the local geo-physical conditions have constrained the spatial direction of expansion. Ulaanbaatar lagged behind Hohhot for about a decade in its total population and urban land (i.e., Ulaanbaatar had the similar level of population and urban land in 2000-2010 as Hohhot in 19902000). The urban environment in both cities has been impacted by urban transformation, with both cities not improving their air pollution indicators. While Hohhot seems to have worse air pollution than Ulaanbaatar in the early 2000s, the gap between the two cities became smaller.

In sum, this research highlights the co-evolution of urbanization, economic development, and environmental change. For Hohhot, the overall trend is that concentrations of air pollutants initially increased and then decreased as GDPpc increased, which can be partly explained by the EKC concept. For Ulaanbaatar, it seems that the city has not reached the tipping point that was suggested by the EKC (air pollution first gets worse but then gets better when GDPpc increases). 
Our research also suggests that larger urban population size does not necessarily mean a worse urban environment. Moreover, our findings indicate that natural variables, such as temperature, precipitation, and green coverage, are associated with air pollution in an unclear way. More analysis is needed to decipher the complex relationship and other coupling factors for modeling air quality. Finally, we emphasize that institutional variables, such as market reform, a household registration system, central government policy on West Region's Development, as well as global market development may have significantly influenced economic development, thus exerting influence on urban expansion. However, at this stage, we do not have enough evidence to quantify their influences.

These findings supported our first hypothesis on variations of urban population, land, and environmental change. However, we do not have strong evidence to support our second and third hypotheses. As mentioned in previous sections, UET and EKC cannot explain the change of urban environment sufficiently. Furthermore, even though there are strong correlations in terms of urbanization and institutional factors, our analysis is limited when assessing the exact impact of these institutional factors.

Finally, the current study shall be viewed and reflected in a larger context of studies on urban sustainability. Wu has advocated that the connections among the key components of an urban landscape and their linkages across spatial (landscape-region-globe) and temporal (year-decadecentury) scales should be taken into account when studying urban sustainability (Wu, 2014, pp. 215, Fig. 4 captions). This research responds by analyzing components and their links across spatial and temporal scales. We highlighted links between green space and air quality indicators of urban environment, the speed and spatio-temporal pattern of urbanization, and economic development and policy intervention of socio-economic processes in two recent decades and in two major cities in the Mongolia Plateau. While key lessons can be learned from this comparative analysis, we realize that there are limitations and is substantial room for future research. For example, we only focused on the expansion of urban built-up land in both cities and did not examine urban forms and urban spatial transformation inside of the boundary of the urban built-up land.

There are several note-worthy research questions that should be addressed in future research such as whether both cities had followed the global trend of landscape structural homogenization or whether there is a "luxury effect", where rich neighborhoods tend to be greener and have a higher level of biodiversity than others (Wu, 2014). In terms of temporal scale, we have focused on only the recent two decades of Hohhot and Ulaanbaatar. However, it should be known that the urban landscape of both cities have evolved for hundreds of years and influences from historic periods and in the early $20^{\text {th }}$ century may have made distinct impressions on their contemporary urban landscape. Furthermore, while both cities may, to a point, have had similar ecological and social histories, they have had undergone very different political changes in the $20^{\text {th }}$ century. Therefore, long-term urban landscape ecological studies are needed to assess the legacy impact on urban landscape as well as to avoid the trend of homogenizing the urban landscape. Finally, strong interactions between urban ecology and urban planning (Wu et al, 2014) and policy interventions are urgently needed when planning for urban sustainability in both cities. 


\section{Acknowledgements}

We would like to acknowledge the financial support from the National Aeronautics and Space Administration (NASA)'s Land Cover and Land Use Program through their grants to Michigan State University (NNX09AI32G, NNX15AD51G, and NNX14AD85G), the "Dynamics of Coupled Natural and Human Systems (CNH)" Program of the NSF (\#1313761), the Natural Science Foundation of China (31229001), and the Asian Development Bank (ADB) through the project "Urbanization in Asia". We thank Huiqing Huang for assistance in data processing of urban expansion of two cities and Hogeun Park for collecting socioeconomic data related to Ulaanbaatar. We also thank Dr. Sereeter Lodyosamba for providing PM2.5 data of Ulaanbaatar. We thank the following people who have assisted us in our field trips in Hohhot and Ulaanbaatar and who have provided insightful comments and suggestions for earlier drafts and the presentation of the paper: Amaraa Amarjargal, Maria Fernandez-Gimenez, Batbuyan Batjav, and Amy Glasmeier. Lastly, we thank Gabriela Shirkey for editing the manuscript. Any opinions, findings, and conclusions or recommendations expressed in this paper are those of the authors and do not necessarily reflect the views of NASA, NSF, or ADB. 


\section{References}

Acemoglu, D., Johnson, S., and Robinson, J. A. (2002). Reversal of fortune: Geography and institutions in the making of the modern world income distribution. The Quarterly Journal of Economics, 117(4), $1231-1294$.

Allen, R. W., Gombojav, E., Barkhasragchaa, B., Byambaa, T., Lkhasuren, O., Amram, O., and Janes, C. R. (2013). An assessment of air pollution and its attributable mortality in Ulaanbaatar, Mongolia. Air Quality, Atmosphere Health, 6(1), 137-150.

Amarbayasgalan, A. (2008). Applications of GIS for urban development and housing in Ulaanbaatar city, Mongolia. Master Student Manuscript, Toyo University.

Amarsaikhan, D., B. Chinbat, M. Ganzorig, V. Battsengel, G. Bulgan, B. Nergui, E. Egshiglen, and R. Gantuya. (2011). Applications of remote sensing (RS) and geographical information system (GIS) for urban land use change study in Ulaanbaatar City, Mongolia. Journal of Geography and Regional Planning 4(8), 471-481.

Amarsaikhan, D., Blotevogel, H. H., and Chinbat, B. (2008). Study on Land Use in Industrial and Green Production Zones of Ulaanbaatar City using Quickbird Image. Map Asia, 2008.

Amarsaikhan, D., Ganzorig, M., Blotevogel, H. H., Nergui, B., and Gantuya, R. (2009). Integrated method to extract information from high and very high resolution RS images for urban planning. Journal of Geography and Regional Planning, 2(10), 258-267.

Asian Development Bank (2008a). Mongolia: Urban Development Sector. Asian Development Bank, Operations Evaluation Department.

Badamdorj, C. (2004). Changes in the Internal Structure of Ulaanbaatar, Mongolia. The Scientific Annual of Korea Mongolian Economic Association.

Bagan, H., Kinoshita, T., and Yamagata, Y. (2009, December). Land cover changes between 1974 and 2008 in Ulaanbaatar, Mongolia. In AGU Fall Meeting Abstracts, 1, 0425.

Bolormaa, T. (2011). Environmental challenges of urbanization and city growth. Background paper for Mongolia Human Development Report 2011. Policy, 4, 4-3.

Chen,W. (2015). The role of urban green infrastructure in offsetting carbon emissions in 35 major cities: A nationwide estimate. Cities, 44, 112-120.

Chen, J., John J. R., Shao, C., Fan, Y., Zhang, Y., Amarjargalj, A., Brown, D., Qi, J., Han, H., Lafortezza, R., and Dong, G. (2015a). Policy shifts influence the functional changes of the CNH systems on the Mongolian Plateau. Environmental Research Letters, doi:10.1088/1748-9326/10/8/085003.

Chen, J., John, R., Zhang, Y., Shao, C., Brown, D. G., Batkhishig, O., Amarjargal, A., Ouyang, Z., Dong, G., Wang, D., and Qi J. (2015b). Divergences of two coupled human and natural systems on the Mongolian Plateau. Bioscience, 65(6), 559-570

Chinbat, B., Bayantur, M., and Amarsaikhan, D. (2006). Investigation of the internal structure changes of Ulaanbaatar city using RS and GIS. In Remote sensing: From pixels to processes' ISPRS Commission VII Mid-term symposium.

Davis, K. (1966). The urbanization of the human population. The city Reader, 1-14.

Davy, P, Gunchin, G., Markwitz, A., Trompetter, W., Barry, B.J., Shagjjamba, D., and Lodyosamba, S. (2011) Air particulate matter pollution in Ulaanbaatar, Mongolia: determination of composition, source contributions and source locations. Atmospheric Pollution Research, 2,126-137. 
Ding, L. and Nelson, W.A.W. (2004). China's West Region Development: Domestic Strategies and Global Implications. Singapore: World Scientific.

Dong, J. J., Zhang, Q., and Niu, J. M. (2008). Changes of land use and its effects on landscape pattern and environment in Hohhot [J]. Journal of Inner Mongolia University, Acta Scientiarum Naturalium Universitatis NeiMongol, 4, 014.

Du, G. (2003). Analysis of land use change in Hohhot. Inner Mongolia Science and Technology 1, 87-89.

Fan, P. and Qi, J. (2010). Assessing the sustainability of major cities in China. Sustainability Science, 5(1), 51-68.

Fan, P., Xie, Y., Qi, J., Chen, J., and Huang, H. (2014). Vulnerability of the coupled natural and human systems in a changing environment: the evolution of Lanzhou's urban landscape. Landscape Ecology, 29(10), 1709-23.

Fan, P., Yue, W., Messina, J., Huang, H., Li, X., Verburg, P., and Qi, J. (2012). Urban expansion in Asia: evaluation, spatial determinants, and future scenarios. Report for the Asian Development Bank (ADB) Project "Urbanization in Asia". Manila: ADB.

Fan, P., Qi, J., Chen, X., Messina, J., Huang, H., and Li, X. (2013). Urban Expansion and Environment Change in Dryland East Asia. In Chen, J., Wan S., Henebry, G., Qi, J., Gutman, G., Kappas, M., Sun, G. (eds) Dryland East Asia (DEA): Land Dynamics amid Social and Climate Change. Beijing: Higher Education Press, Chapter 5.

Gong, C., Yu, S., Joesting, H., and Chen, J. (2013). Determining socioeconomic drivers of urban forest fragmentation with historical remote sensing images. Landscape and Urban Planning, 117, 57-65.

Guo J, Deng, M., Fan, J., Li, Z., Chen, Q, Zhai, P., Dai, Z., and Li, X. (2014). "Precipitation and Air Pollution at Mountain and Plain Stations in Northern China: Insights Gained from Observations and Modeling." Journal of Geophysical Research. D. (Atmospheres), 119(8), 4793 4807. doi:10.1002/2013JD021161

Guttikonda, S.K., Lodyosamba, S., Bulgansaikhan, B., and Dashdondog, B. (2013). Air Quality, Atmosphere Health, 6, 589-601.

Guttikunda, S. (2007). Urban air pollution analysis for Ulaanbaatar. The World Bank Consultant Report, 1-132.

Herro, M., Naidan, O. Erdene, M., Lkhagva, A., Shagdarsuren, S., Samdantsoodol, S., Chimidhisig, M., Jadamba, U., Tumurbaaatar O., and Lookhondorj, T. (2003). Ulaanbaatar Rapid Needs Assessment. "The GER Initiative" USAID/CHF Growing Entrepreneurship Rapidly Initiative.

Huang, Y. K., Luvsan, M. E., Gombojav, E., Ochir, C., Bulgan, J., and Chan, C. C. (2013). Land use patterns and $\mathrm{SO}_{2}$ and $\mathrm{NO}_{2}$ pollution in Ulaanbaatar, Mongolia. Environmental Research, 124, 1-6.

Huang, Y.K., Luvsan, M-E, Gombojav, E., Ochir, C., Bulgan, J., and Chan, C-C. (2013). Land use patterns and $\mathrm{SO}_{2}$ and $\mathrm{NO}_{2}$ polution in Ulaanbaatar, Mongolia. Environmental Research, 124, 1-6, doi: 10.1016/j.envres.2013.02.006.

Ji, X., Chen, T., and Zeng, F. (2009). Ecological environment in peri-urbanized area. Ecology and Environmental Sciences, 18(4), 1579-86.

Jiang Z.Y., Huete A. R., Didan K., and Miura T. (2008). Development of a two-band enhanced vegetation index without a blue band. Remote Sensing of Environment, 112 3833-45. 
John, R., Chen, J., Ouyang, Z., Xiao, J., Becker, R., Samanta, A. Ganguly, S., Yuan, W., and Batkhshig, O. (2013). Vegetation response to extreme climate events on the Mongolian plateau from 2000-2010. Environmental Research Letters, 8, 035033, doi:10.1088/1748-9326/8/3/035033.

Liu, J., Hull, V., Batistella, M., DeFries, R., Dietz, T., Fu, F., Hertel, T. W., Izaurralde, R. C., Lambin, E. F., Li, S., Martinelli, L. A., McConnell, W. J., Moran, E. F., Naylor, R., Ouyang, Z., Polenske, K. R., Reenberg, A., Rocha, G. de Miranda, Simmons, C. S., Verburg, P. H., Vitousek, P. M., Zhang, F. and Zhu, C. (2013). Framing sustainability in a telecoupled world. Ecology Society, 18(2), 26.

Liu, Y., Yue, W., and Fan, P. (2011). Spatial determinants of urban land conversion in large Chinese cities: a case of Hangzhou. Environment and Planning-Part Bulletin, 38(4), 706-725.

Luo, C. (2000). Effects of land use change on ecological consequences in Holhot. Master dissertation. Hohhot, Inner Mongolia University.

Luvsan M,-E., Shie R.-H., Purevdorj T., Badarch, L., Baldorj, B., and Chan C.-C. (2012). The influence of emission sources and meteorological conditions on $\mathrm{SO}_{2}$ pollution in Mongolia. Atmospheric Environment, 61, 542-549, doi:10.1016/j.atmosenv.2012.07.044http://dx.doi.org/10.1016/j.atmosenv.2012.07.044

Mei, R. and Hai, J. (2009). GIS-based Markov Simulation for urban spatial transformation. Inner Mongolia Science Technology Economy, 24, 56-57.

Mei, R. and Han, L. (2010). Spatio-temporal differentiation of urban land use in Hohhot. The Border Economy Culture, 8, 20-21.

Miller, J. E. (2013). Nomadic and domestic: Dwelling on the edge of Ulaanbaatar, Mongolia. University of California, Los Angeles.

National Statistical Office of Mongolia (NSOM), 2015. Available at www.nso.mn/, accessed from Jan. 1 - Apr. 15, 2015.

Pickett, S. T. A., Burch, W. R., Dalton, S. E., Foresman, T. W., Grove, J. M., and Rowntree, R. (1997). A conceptual framework for the study of human ecosystems in urban areas. Urban Ecosystems, 1, 185199.

Portney, K. E. (2003). Taking sustainable cities seriously: Economic development, the environment, and quality of life in American cities. Cambridge, MA: MIT Press.

Qi, J., Chen, J., Wan, S., and Ai, L. (2012). Understanding the coupled natural and human systems in Dryland East Asia. Environmental Research Letters, 7(1), 015202.

Rabinovitch, J. and Leitman, J. (1996). Urban planning in Curitiba. Scientific American, 274(3), 46-53.

Sankey TT, Sankey JB, Weber KT, and Montagne C. (2009). Geospatial Assessment of Grazing Regime Shifts and Sociopolitical Changes in a Mongolian Rangeland. Rangeland Ecology Management 62(6), $522-530$

Schran, P. (2014). Mongolia's Economic Development in the context of Northeast Asian Economic Cooperation. Mongolian Journal of International Affairs, 6, 50-63.

Schneider, A., Woodcock, C. E. (2008). Compact, dispersed, fragmented, extensive? Urban Studies 45, 659-92.

Sonomjamts, M., Dashdemberel, S., Logii, N., Nakae, K., Chigusa, Y., Ohhira, S., and Makino, S. (2014). Prevalence of asthma and allergic rhinitis among adult population in Ulaanbaatar, Mongolia. Asia Pacific Allergy, 4(1), 25. 
Stern DI. (2004). The rise and fall of the environmental Kuznets curve. World Development, 32(8): 141939.

Sun, X. (2005). Impact of meteorological conditions on air pollution in Hohhot. Environment Protection in Inner Mongolia, 17(1), 17-23. ;

Tsogtsaikhan, B. (2003). Migration, urbanization and development in Mongolia. Economic and social commission for Asia and the Pacific Conference. ESID/EGM/INF. 15 August 2003.

UNDP. (2011). From vulnerability to sustainability: Environment and Human Development. Mongolia Human Development Report 2011.

Wang, J. (1997). Concerning the ethnic moving and living structures in the urban area of Hohhot [J]. Northwest Minorities Research, 2, 7-29.

Wang, S, Yuan, W., and Sheng, K. (2006). The impacts of different kinds of dust events on $\mathrm{PM}_{10}$ pollution in Northern China. Atmospheric Environment, 40, 7975-7982.

Warburton, D., Gilliland, F., and Dashdendev, B. (2013). Environmental pollution in Mongolia: effects across the lifespan. Environmental Research, 124, 65.

Wheeler, S. M. and Beatley, T. (Eds.). (2004). The sustainable urban development reader (p. 486). New York: Routledge.

World Bank. (2004). Environmental challenges of urban development. Mongolia environment monitor.

World Bank. (2015). World Development Indicator. Available at data.worldbank.org, accessed in March $1,2015$.

Wu, J. (2010). Urban sustainability: An inevitable goal of landscape research. Landscape Ecology, 25, 14.

Wu, J. (2014). Urban ecology and sustainability: the state-of-the-science and future directions. Landscape and Urban Planning, 125, 209-221.

Wu, J., Xiang, W. N., and Zhao, J. (2014). Urban ecology in China: Historical developments and future directions. Landscape and Urban Planning, 125, 222-233.

Yue, W., Liu, Y., and Fan, P. (2010). Polycentric urban development: the case of Hangzhou. Environment and Planning. A, 42(3), 563-577.

Zhang, J., Chang, X., Li, J. and Cai, M. (2008). Land use change and its ecological effect in Hohhot city based on 3S technology. Chinese Journal of Ecology, 27(12): 2184-2187.

Zhou, K., Ye, Y.H., Liu, Q., Liu, A.J., and Peng, S. L. (2007). Evaluation of ambient air quality in Guangzhou, China. Journal of Environmental Sciences, 19(4), 432-437. 


\section{Tables}

Table 1. Correlation matrix (Hohhot/Ulaanbaatar).

\section{Figures}

Figure 1. Conceptual framework for understanding the complex relationships among the physical, socioeconomic, and environmental conditions in the two urban systems.

Figure 2. Urban expansion of Hohhot and Ulaanbaatar, 1990-2010. The urban built-up areas clustered north of the Yellow River and the Tuul River for Hohhot and Ulaanbaatar, respectively. Hohhot (left) expanded much faster during 2000-2010 than that during 1990-2000. While development occurred mostly along the eastern urban fringe area from 1990 to 2000, urban builtup lands were added to the rest of the urban periphery area from 2000 to 2010 . The settlement areas in the northern hilly areas accounted for most of Ulaanbaatar's urban expansion (right). The newly added urban built-up areas were concentrated in the original agricultural lands along the Tuul River and the mountainous areas in the north, within the traditional Ger areas.

Figure 3. Urbanization in Hohhot and Ulaanbaatar (UB) in 1990, 2000, and 2010.

Figure 4. Changes in $\mathrm{NO}_{2}, \mathrm{SO}_{2}, \mathrm{AOT} 342$, AOT 483, $\mathrm{PM}_{10}$ and $\mathrm{PM}_{2.5}$ in Hohhot and Ulaanbaatar (UB).

Figure 5. Changes in $\mathrm{PM}_{2.5}$ in Ulaanbaatar during 2004-2014.

Figure 6. Relationship between urban population growth and economic development for Hohhot (1978-2011) and Ulaanbaatar (UB) (2000-2013). Gross domestic product per capita (GDPpc) is in USD 2005.

Figure 7. Contribution of major sectors to Gross domestic product (GDP) in Hohhot (20032011) (Fig. 7a) and Ulaanbaatar (2000-2013) (Fig. 7b).

Figure 8. Changes in urban population, economic development, and air pollution in Hohhot (2003-2011) and Ulaanbaatar (UB) (2000-2013).

Figure 9. Climate and biophysical characters and air pollution in Hohhot and Ulaanbaatar (UB) (a) Precipitation and air pollution (left: annual precipitation; right: June, July, and August (JJA) precipitation).

(b) Temperature and air pollution (left: June, July, and August (JJA) mean temperature; right:

December, January, and February (DJF) mean temperature)

(c) Urban greenness and air pollution (left: growing season max EVI2 spatial mean; right: growing season max NDVI spatial mean)

Figure 10. Impact of institutional interventions on urbanization and the economic development of Hohhot and Ulaanbaatar (UB). 
Table 1. Correlation matrix of quantitative variables for Hohhot and Ulaanbaatar (shaded texts). The two cities have a different standard of Particular Matter data: Ulaanbaatar data consist of PM2.5 annual and PM2.5 DJF, while Hohhot data is based on PM10. The bolded values are significant relationship at $\mathrm{p}=0.05$.

\begin{tabular}{|c|c|c|c|c|c|c|c|c|c|c|c|c|c|c|c|c|c|c|c|}
\hline & & \multirow{2}{*}{ Year } & \multirow{2}{*}{$\begin{array}{l}\text { Max } \\
\text { EVI2 }\end{array}$} & \multirow{2}{*}{$\begin{array}{l}\text { EVI2 } \\
\text { JJA } \\
\text { mean }\end{array}$} & \multirow{2}{*}{$\begin{array}{l}\text { PDSI } \\
\text { JJA } \\
\text { mean }\end{array}$} & \multirow{2}{*}{$\begin{array}{l}\text { NDVI } \\
\text { JJA } \\
\text { mean }\end{array}$} & \multirow{2}{*}{$\begin{array}{l}\text { Max } \\
\text { NDV } \\
\text { I2 }\end{array}$} & \multirow{2}{*}{$\begin{array}{c}\text { PREC } \\
\text { TOT } \\
\text { JJA } \\
\text { mean }\end{array}$} & \multirow{2}{*}{$\begin{array}{l}\mathrm{T} 2 \mathrm{~m} \\
\mathrm{JJA} \\
\text { mean }\end{array}$} & \multirow{2}{*}{$\begin{array}{l}\text { DJF } \\
\text { Tair }\end{array}$} & \multirow{2}{*}{$\begin{array}{c}\text { CRU } \\
\text { Annual } \\
\text { Acc. } \\
\text { prec. }\end{array}$} & \multirow{2}{*}{$\begin{array}{c}\text { AOT } \\
483\end{array}$} & \multirow{2}{*}{$\begin{array}{c}\text { АOT } \\
342\end{array}$} & \multirow{2}{*}{$\mathrm{SO}_{2}$} & \multirow{2}{*}{$\mathrm{NO}_{2}$} & \multicolumn{2}{|c|}{$\mathrm{PM}_{10}$} & \multirow{2}{*}{$\begin{array}{c}\text { GDP } \\
\mathrm{pc}\end{array}$} & \multirow{2}{*}{$\begin{array}{c}\text { Urban } \\
\text { Pop } \\
\text { thousand }\end{array}$} \\
\hline & & & & & & & & & & & & & & & & $\begin{array}{c}\mathrm{PM}_{2.5} \\
\text { annual } \\
\end{array}$ & $\begin{array}{c}\mathrm{PM}_{2.5} \\
\mathrm{DJF}\end{array}$ & & \\
\hline \multirow{2}{*}{\multicolumn{2}{|c|}{ Year }} & \multirow{2}{*}{1} & 0.55 & 0.48 & -0.12 & 0.10 & 0.26 & -0.19 & 0.36 & 0.09 & -0.17 & -0.38 & -0.41 & -0.09 & 0.66 & \multicolumn{2}{|c|}{ annual } & DJF & 0.97 \\
\hline & & & -0.31 & -0.43 & -0.17 & -0.47 & -0.29 & -0.73 & 0.78 & 0.27 & -0.06 & 0.5 & 0.54 & 0.59 & 0.85 & 0.63 & 0.51 & 0.92 & 0.96 \\
\hline \multirow{2}{*}{\multicolumn{2}{|c|}{ Max EVI2 }} & & 1 & 0.97 & 0.27 & 0.71 & 0.83 & 0.27 & -0.08 & 0.04 & 0.07 & 0.29 & 0.24 & -0.4 & -0.43 & \multicolumn{2}{|c|}{0.34} & 0.24 & 0.47 \\
\hline & & & 1 & 0.96 & 0.19 & 0.67 & 0.82 & 0.14 & -0.2 & -0.24 & -0.15 & -0.4 & -0.46 & -0.43 & -0.55 & -0.32 & -0.6 & -0.72 & -0.59 \\
\hline & & & & & 0.3 & 0.69 & 0.84 & 0.22 & -0.11 & - & 0.1 & 0.11 & 0.02 & $\begin{array}{l}-0.38 \\
\end{array}$ & $\begin{array}{c}-0.32 \\
\end{array}$ & & & 0.23 & 0.42 \\
\hline & & & & 1 & 0.23 & 0.7 & 0.78 & 0.19 & -0.27 & - & -0.13 & -0.4 & -0.47 & -0.48 & -0.58 & -0.27 & - & -0.65 & -0.65 \\
\hline & & & & & & 0.32 & 0.34 & 0.34 & -0.47 & - & -0.17 & -0.26 & -0.69 & -0.81 & -0.46 & & & -0.22 & -0.19 \\
\hline & & & & & 1 & 0.17 & 0.47 & 0.35 & -0.37 & - & 0.22 & 0.19 & 0.27 & 0.01 & 0.16 & 0.87 & - & 0.5 & -0.17 \\
\hline & & & & & & 1 & 0.77 & 0.27 & -0.14 & - & 0.01 & 0.02 & -0.19 & -0.47 & -0.39 & & & 0.03 & 0.09 \\
\hline & & & & & & 1 & 0.72 & 0.17 & -0.3 & - & 0.01 & 0.03 & -0.08 & -0.03 & -0.15 & -0.39 & - & -0.3 & -0.64 \\
\hline & & & & & & & 1 & 0.28 & -0.12 & 0 & 0.32 & -0.11 & -0.23 & -0.33 & -0.11 & & & 0.08 & 0.18 \\
\hline & & & & & & & 1 & 0.22 & -0.31 & -0.2 & 0.05 & 0.11 & 0.04 & -0.06 & -0.09 & -0.06 & -0.28 & -0.12 & -0.5 \\
\hline & & & & & & & & & -0.72 & - & 0.13 & 0.18 & 0 & -0.51 & -0.57 & & & -0.32 & -0.24 \\
\hline & & & & & & & & 1 & -0.78 & - & 0.03 & -0.6 & -0.52 & -0.6 & -0.51 & 0.5 & - & -0.11 & -0.34 \\
\hline & & & & & & & & & & - & -0.19 & -0.08 & 0.07 & 0.58 & 0.44 & & & 0.37 & 0.38 \\
\hline & & & & & & & & & 1 & - & -0.23 & 0.24 & 0.21 & 0.36 & 0.34 & -0.55 & - & -0.07 & 0.62 \\
\hline & & & & & & & & & & & -0.25 & -0.2 & -0.17 & 0.17 & 0.09 & & & 0.09 & 0.06 \\
\hline & & & & & & & & & & 1 & 0.05 & 0.24 & 0.18 & 0.21 & 0.27 & -0.37 & 0.77 & 0.01 & -0.18 \\
\hline CRU. A & al Acc & & & & & & & & & & & -0.18 & 0.04 & -0.35 & 0.4 & & & -0.08 & -0.19 \\
\hline & & & & & & & & & & & 1 & 0.32 & 0.31 & -0.25 & -0.03 & 0.22 & 0.24 & 0.08 & -0.12 \\
\hline & & & & & & & & & & & & 1 & 0.94 & 0.35 & -0.19 & & & -0.09 & -0.12 \\
\hline & & & & & & & & & & & & 1 & 0.99 & 0.52 & 0.75 & 0.37 & 0.03 & 0.74 & 0.77 \\
\hline & & & & & & & & & & & & & 1 & 0.29 & -0.18 & & & -0.13 & -0.1 \\
\hline & & & & & & & & & & & & & 1 & 0.56 & 0.78 & 0.43 & 0.04 & 0.74 & 0.8 \\
\hline & & & & & & & & & & & & & & & 0.48 & & & 0.69 & 0.66 \\
\hline & & & & & & & & & & & & & & 1 & 0.8 & 0.24 & 0.35 & 0.43 & 0.55 \\
\hline & & & & & & & & & & & & & & & & & & 0.93 & 0.93 \\
\hline & & & & & & & & & & & & & & & 1 & 0.48 & 0.35 & 0.86 & 0.89 \\
\hline & & & & & & & & & & & & & & & & 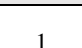 & - & -0.51 & -0.61 \\
\hline $\mathrm{PM}_{10}$ & annual & & & & & & & & & & & & & & & 1 & -0.08 & $\mathbf{0 . 5 3}$ & 0.64 \\
\hline & $\mathrm{PM}_{2.5}$ & & & & & & & & & & & & & & & & 1 & - & - \\
\hline
\end{tabular}




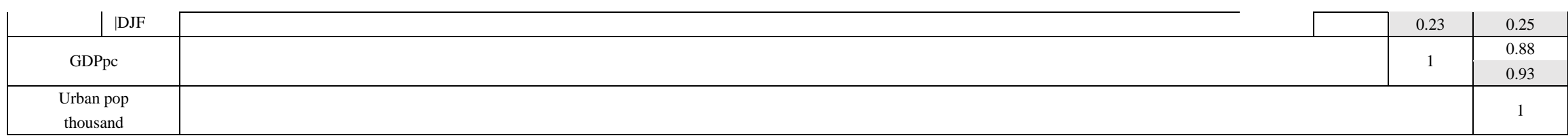

Note:

PREC TOT JJA: total precipitation in June, July, and August;

T2m JJA: temperature at $2 \mathrm{~m}$ in June, July, and August;

DJF Tair: air temperature in December, January, and February;

CRU Annual Acc Prec: CRU annual accumulated precipitation. 


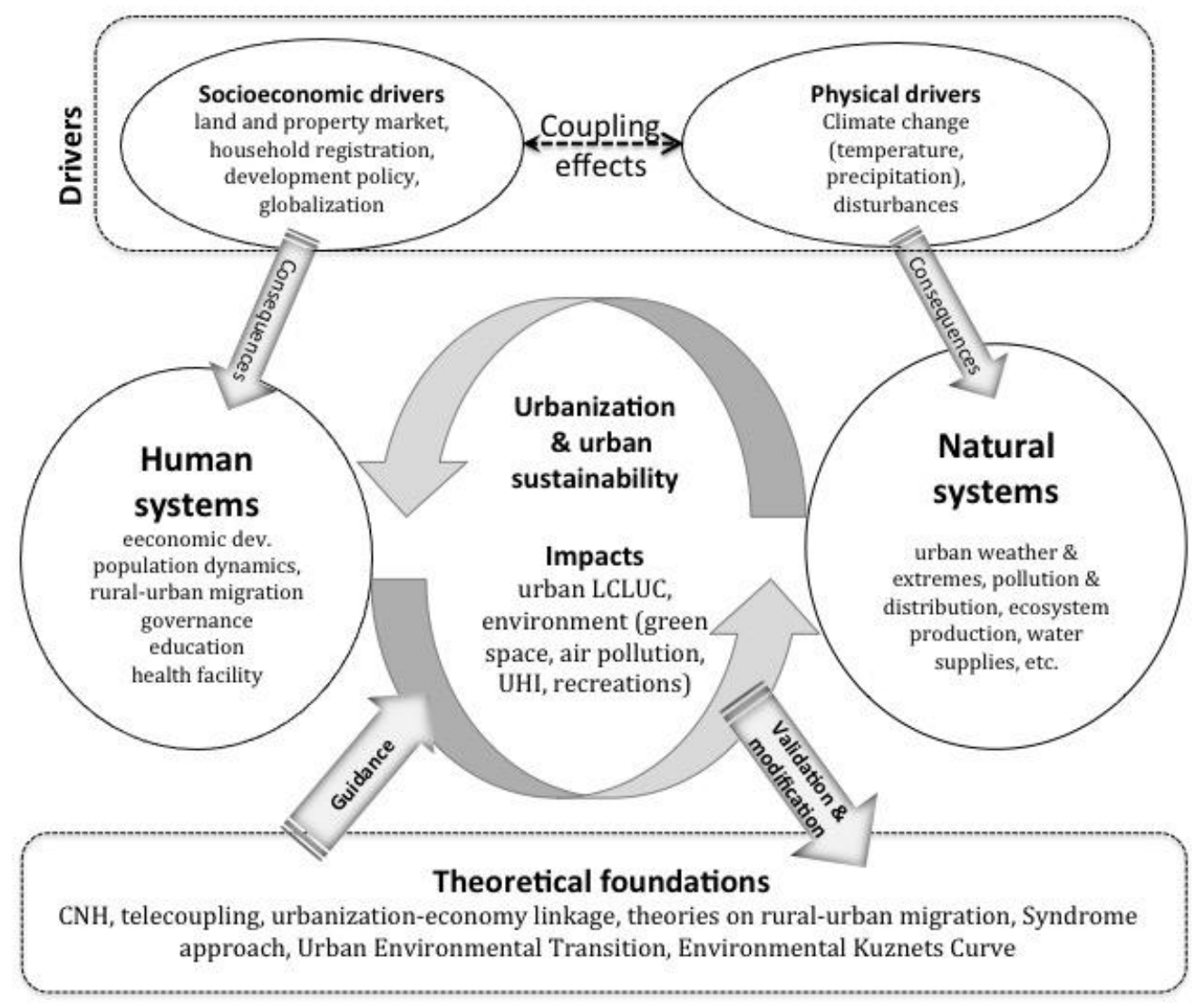

Fig. 1 


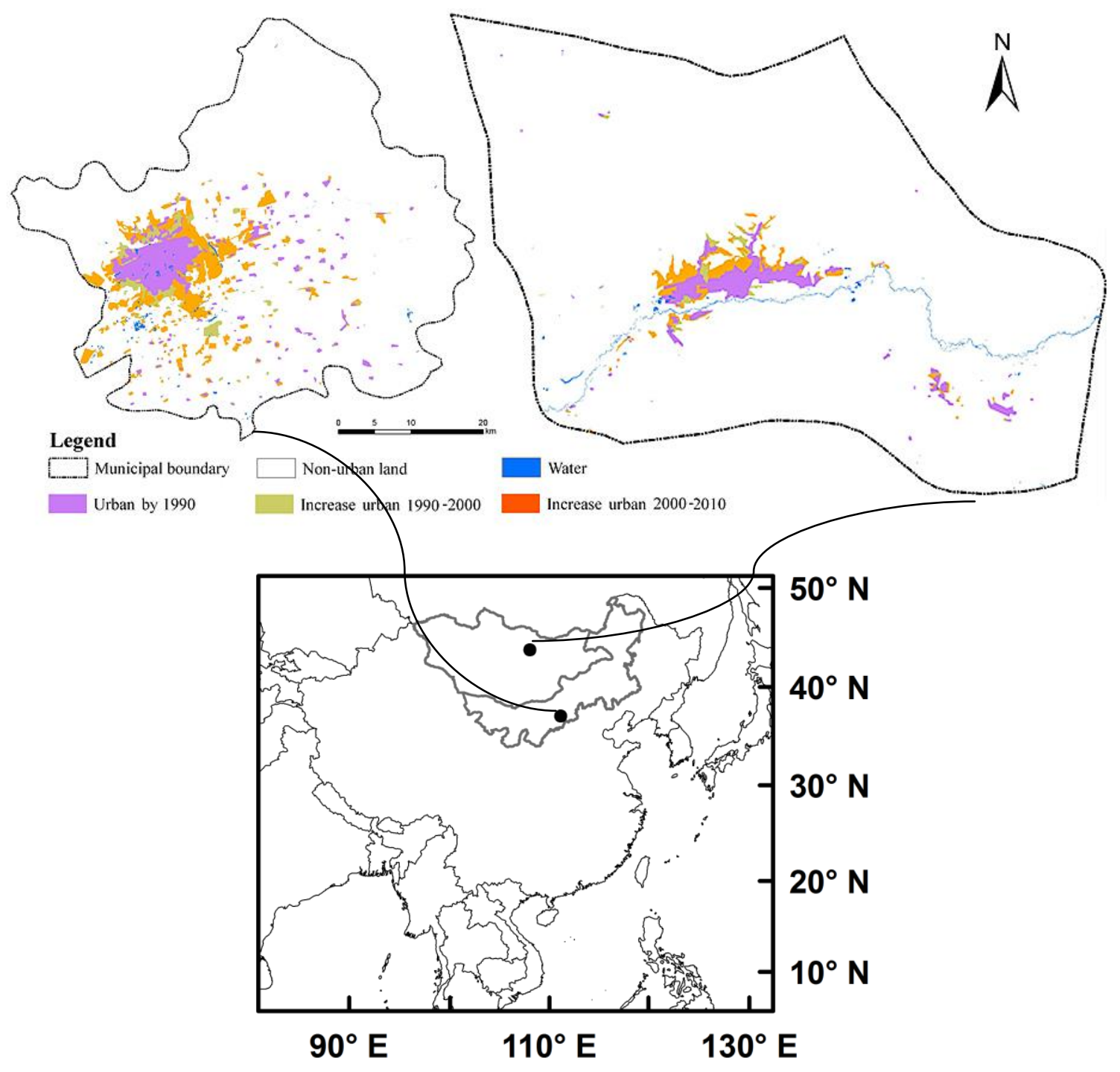

Fig. 2 


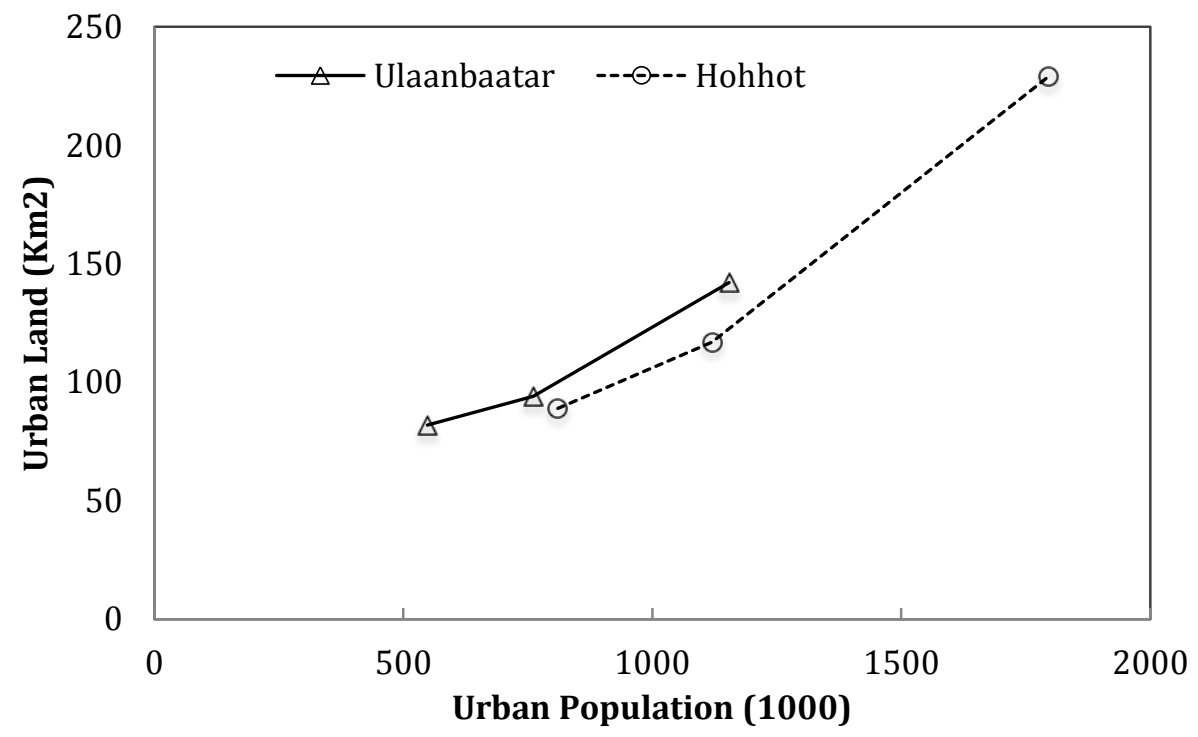

Fig. 3 

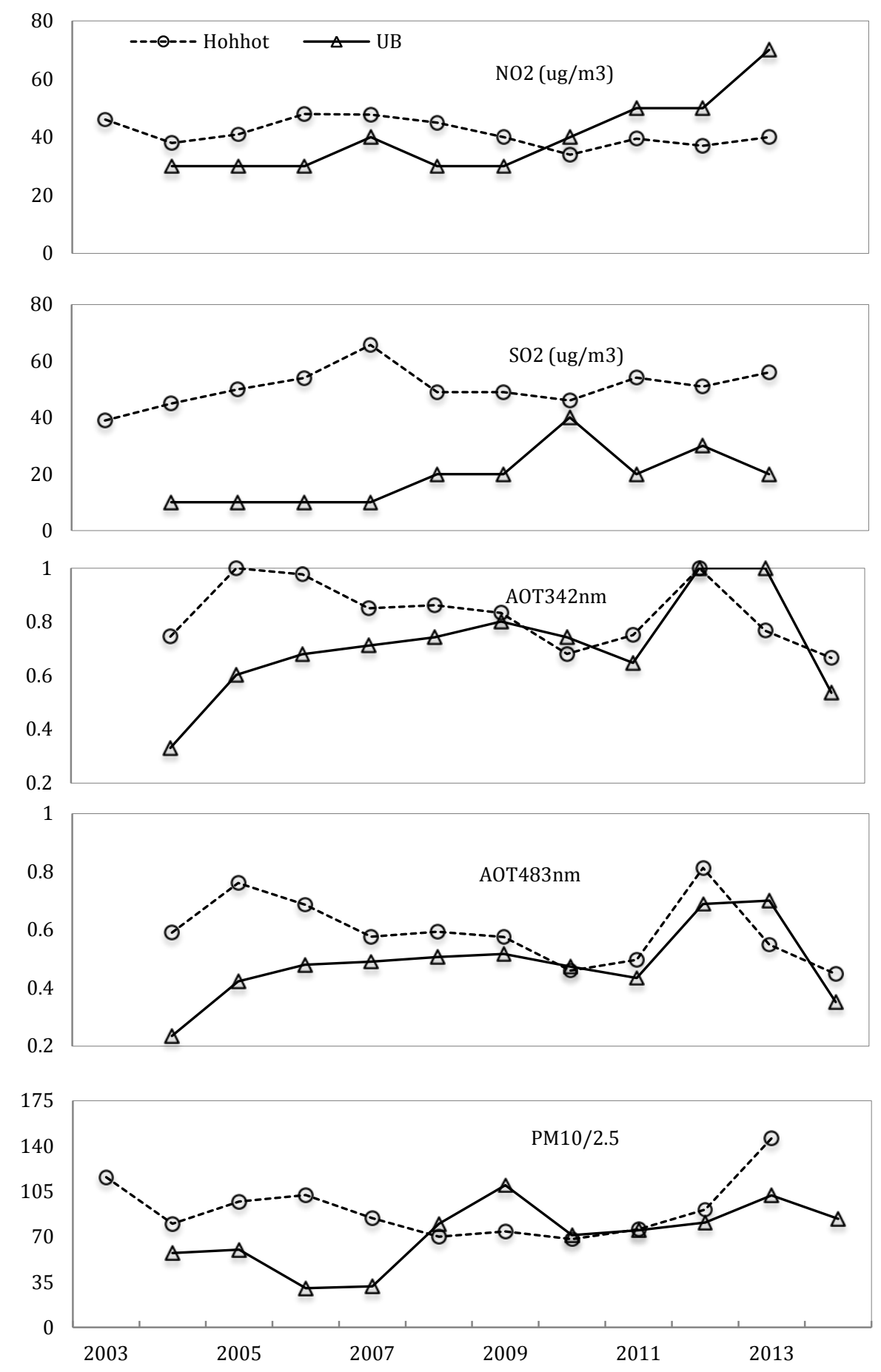

Fig. 4 


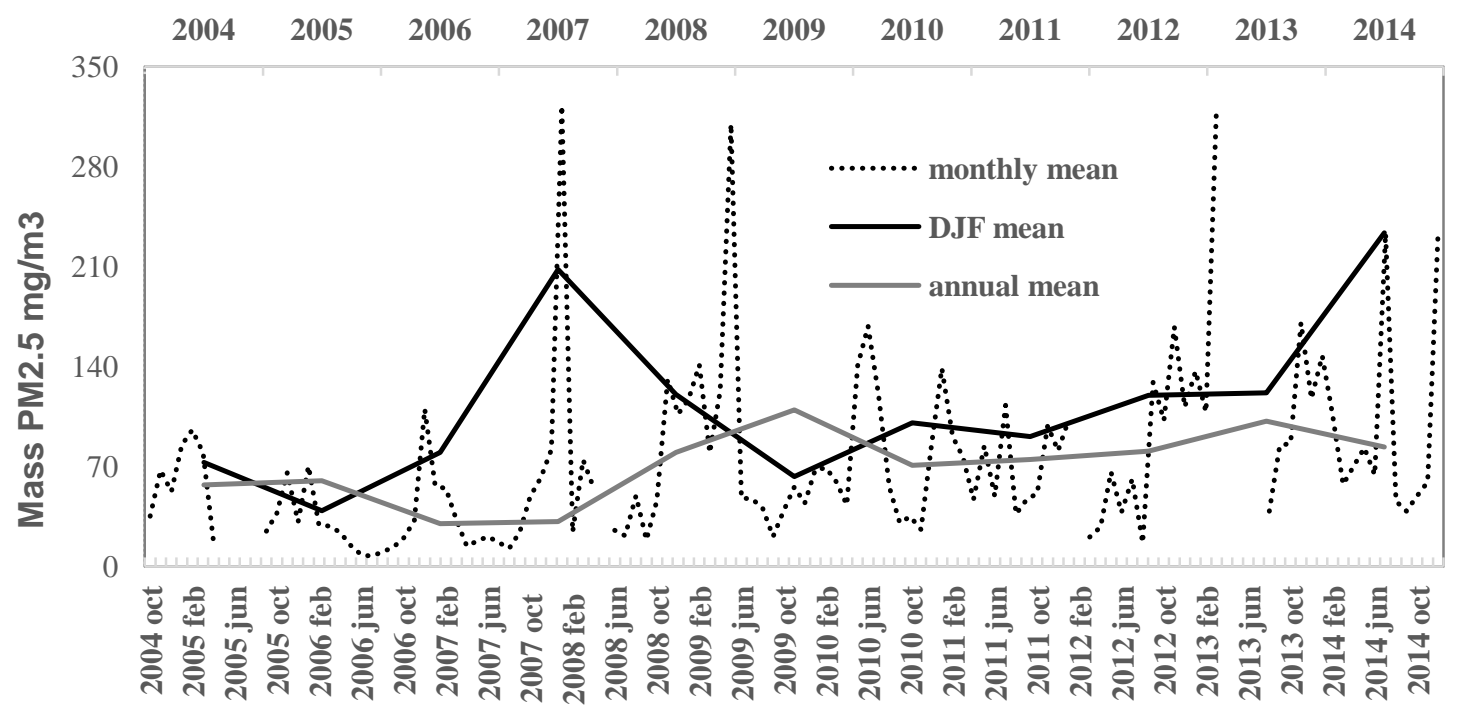

Fig. 5 


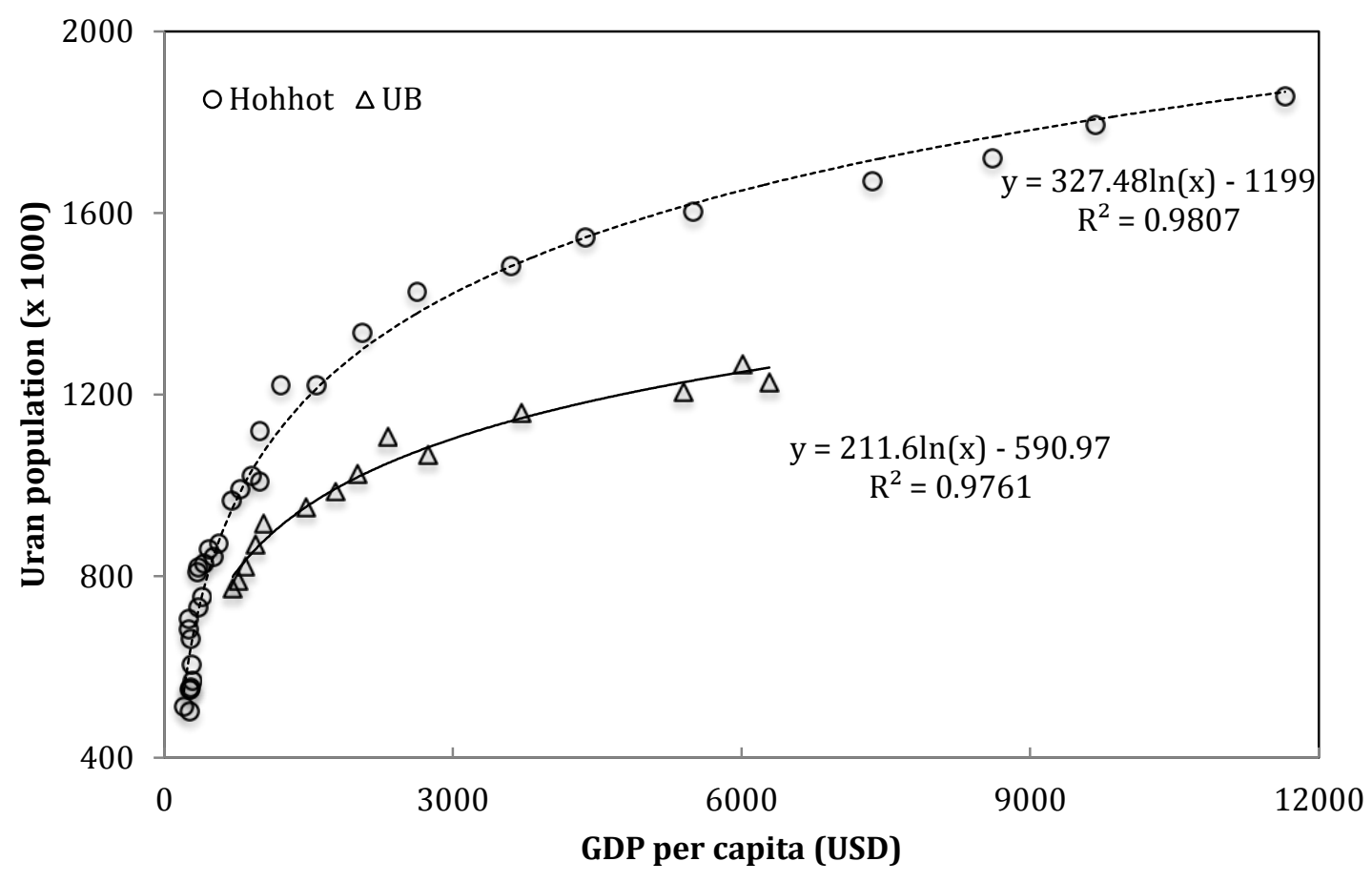

Fig. 6 


\section{Hohhot}
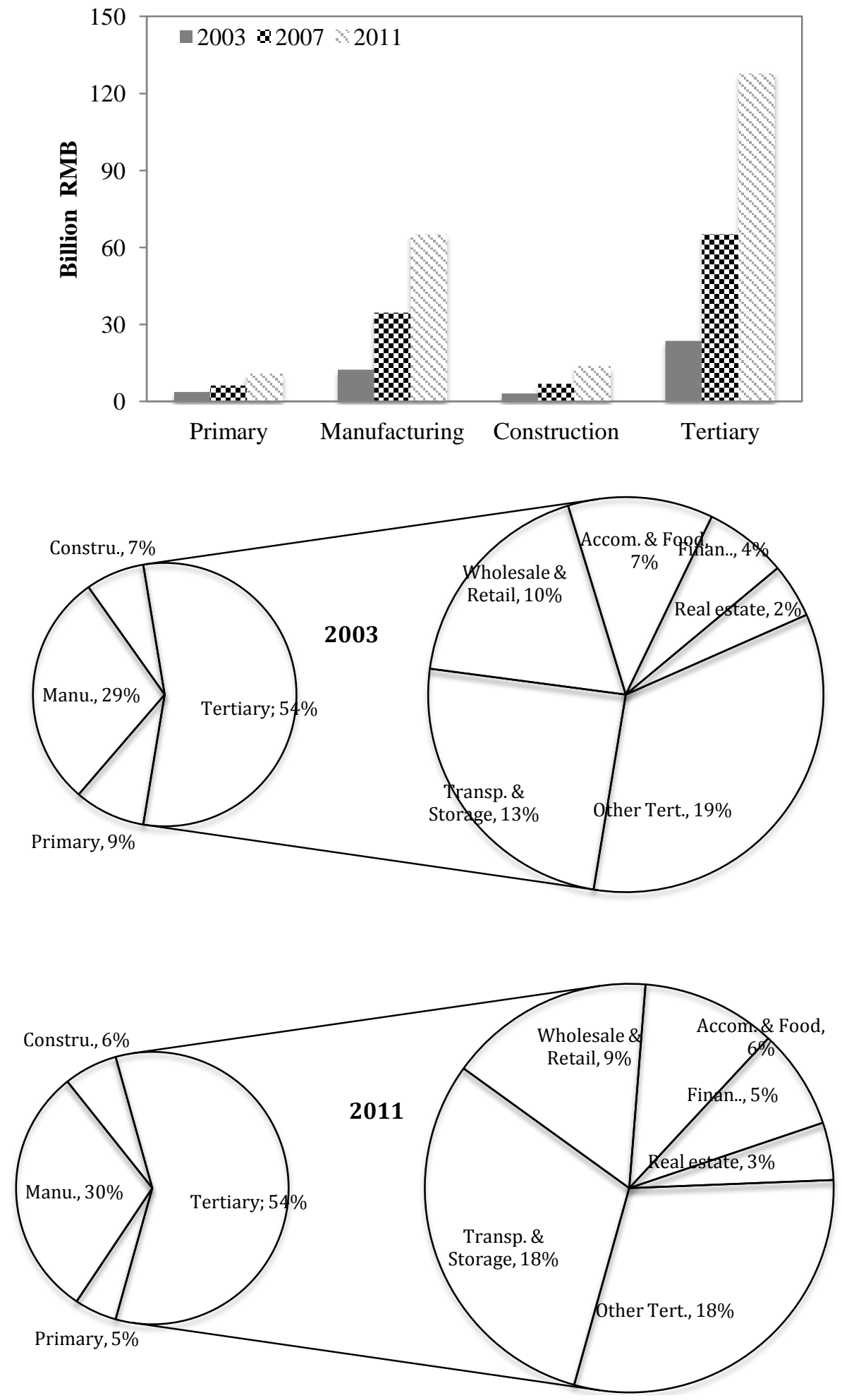

Fig. 7a 

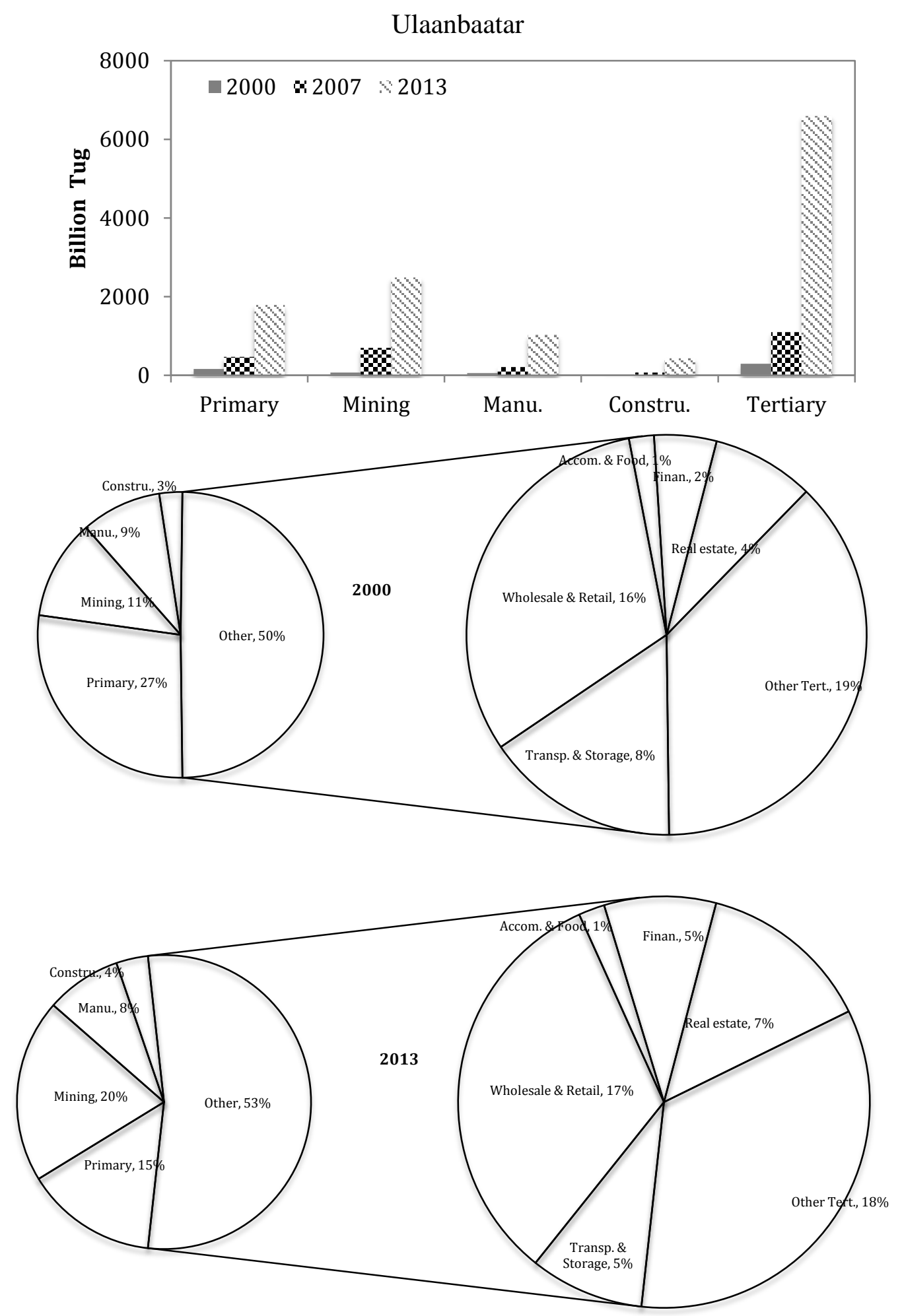

Fig. $7 b$ 

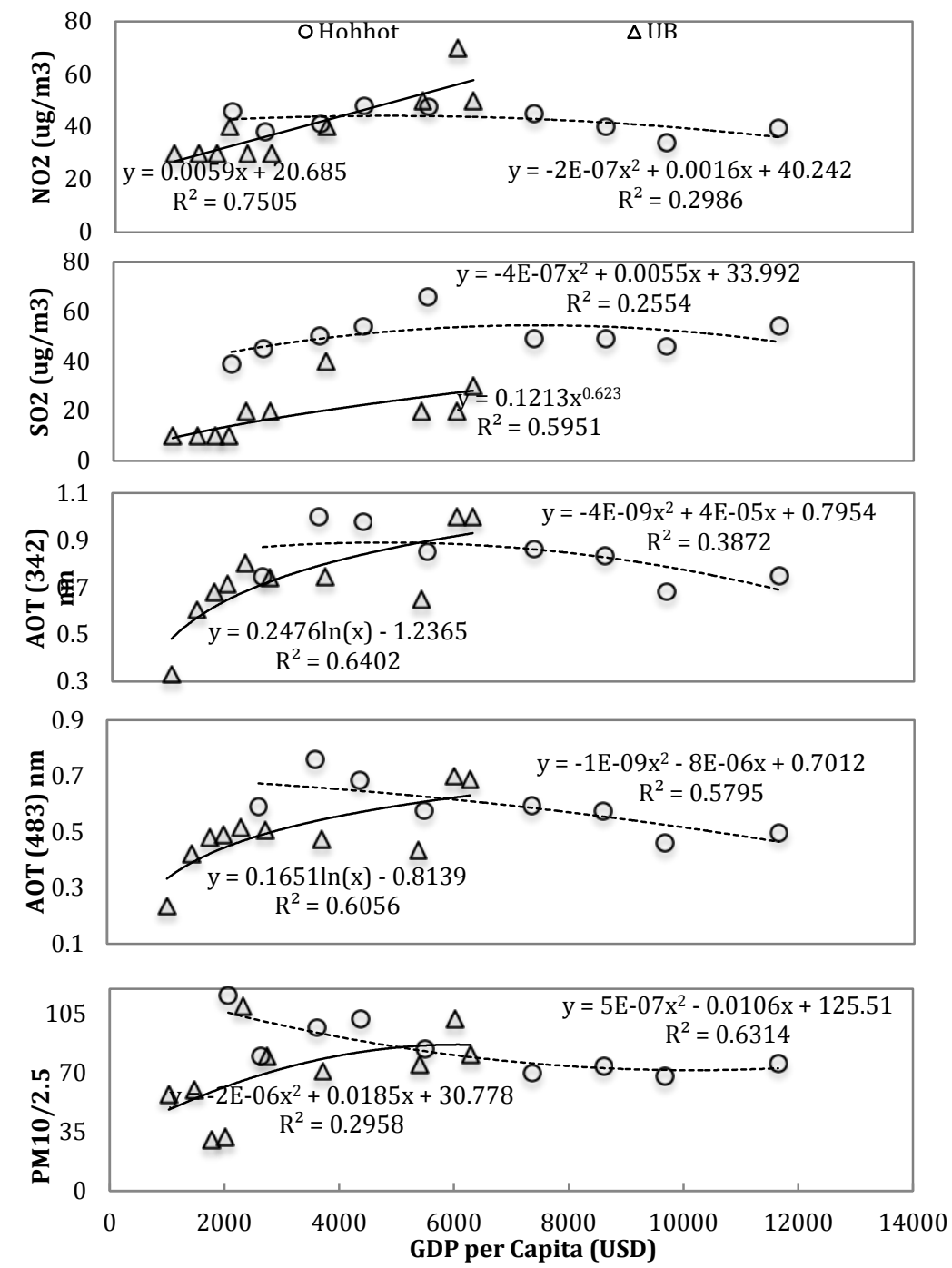

Fig. 8
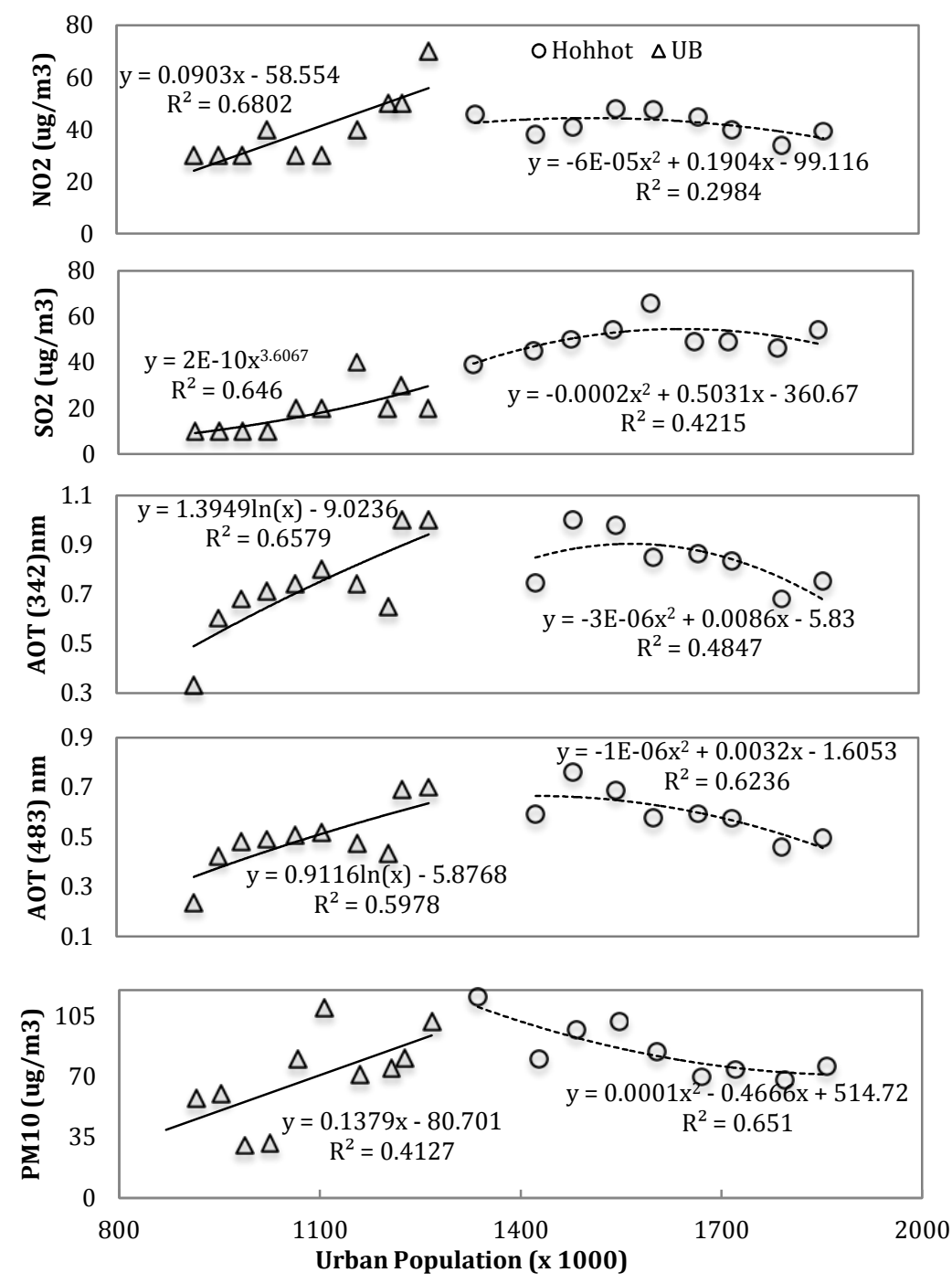

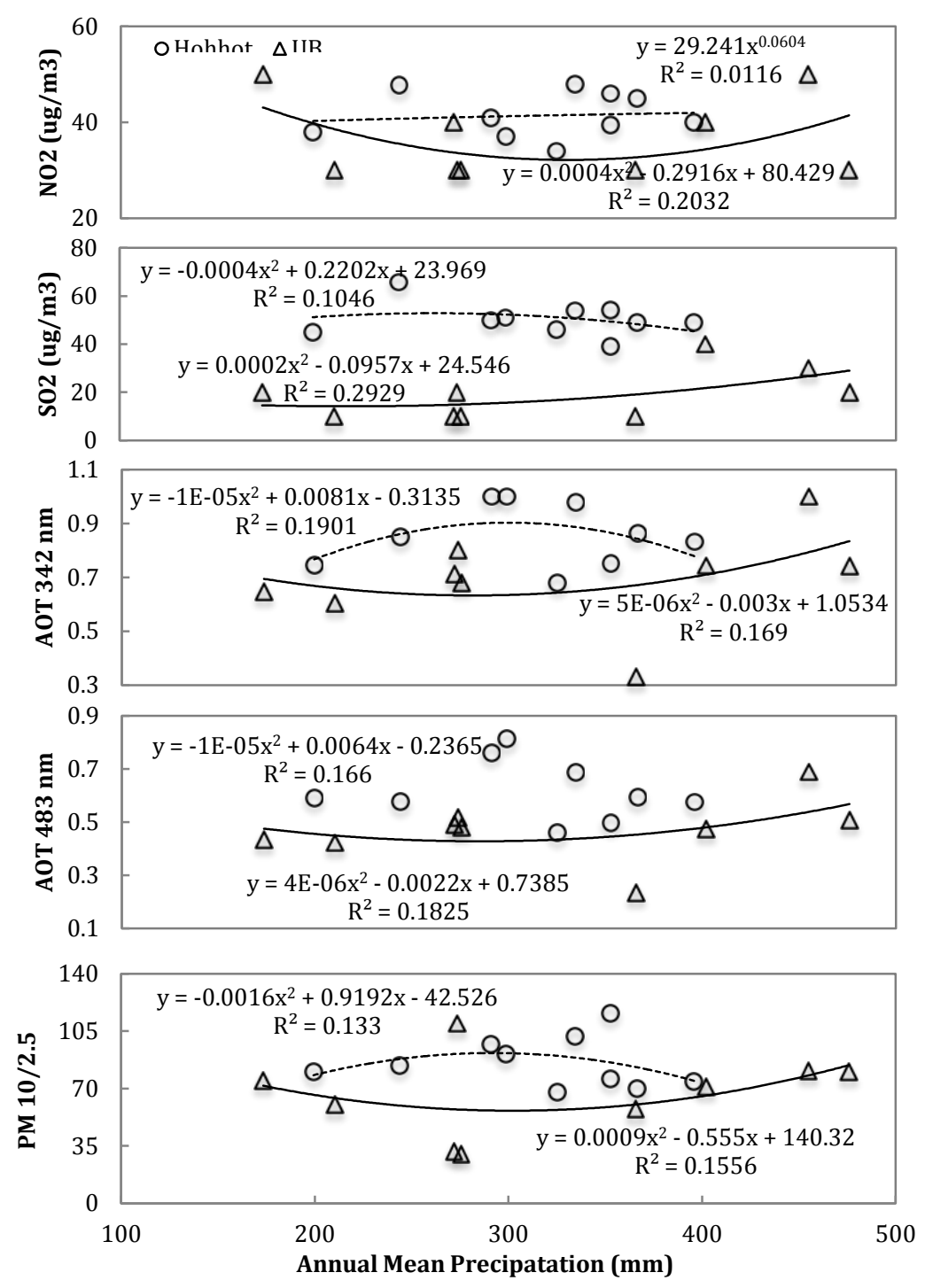
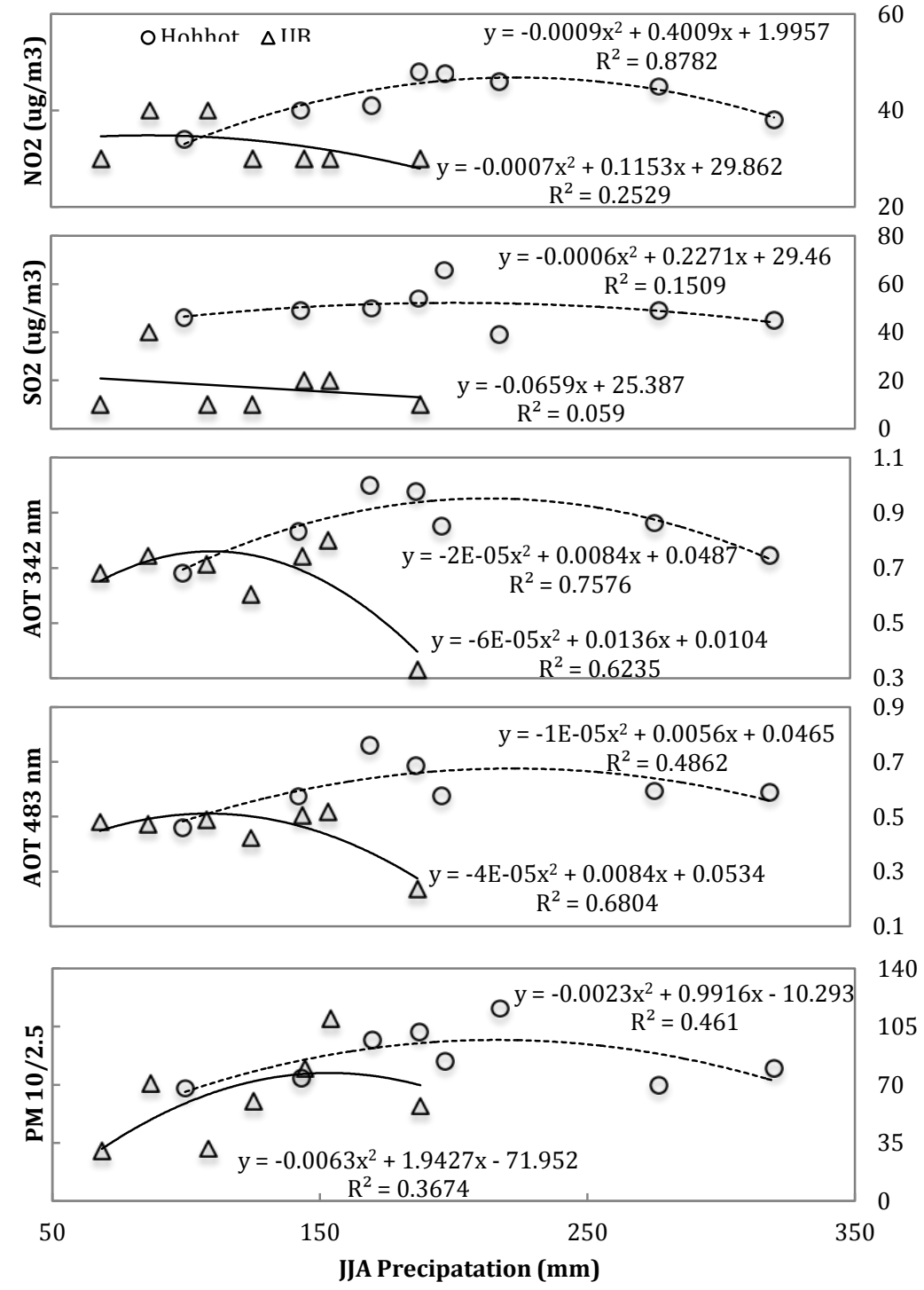

Fig. 9a 

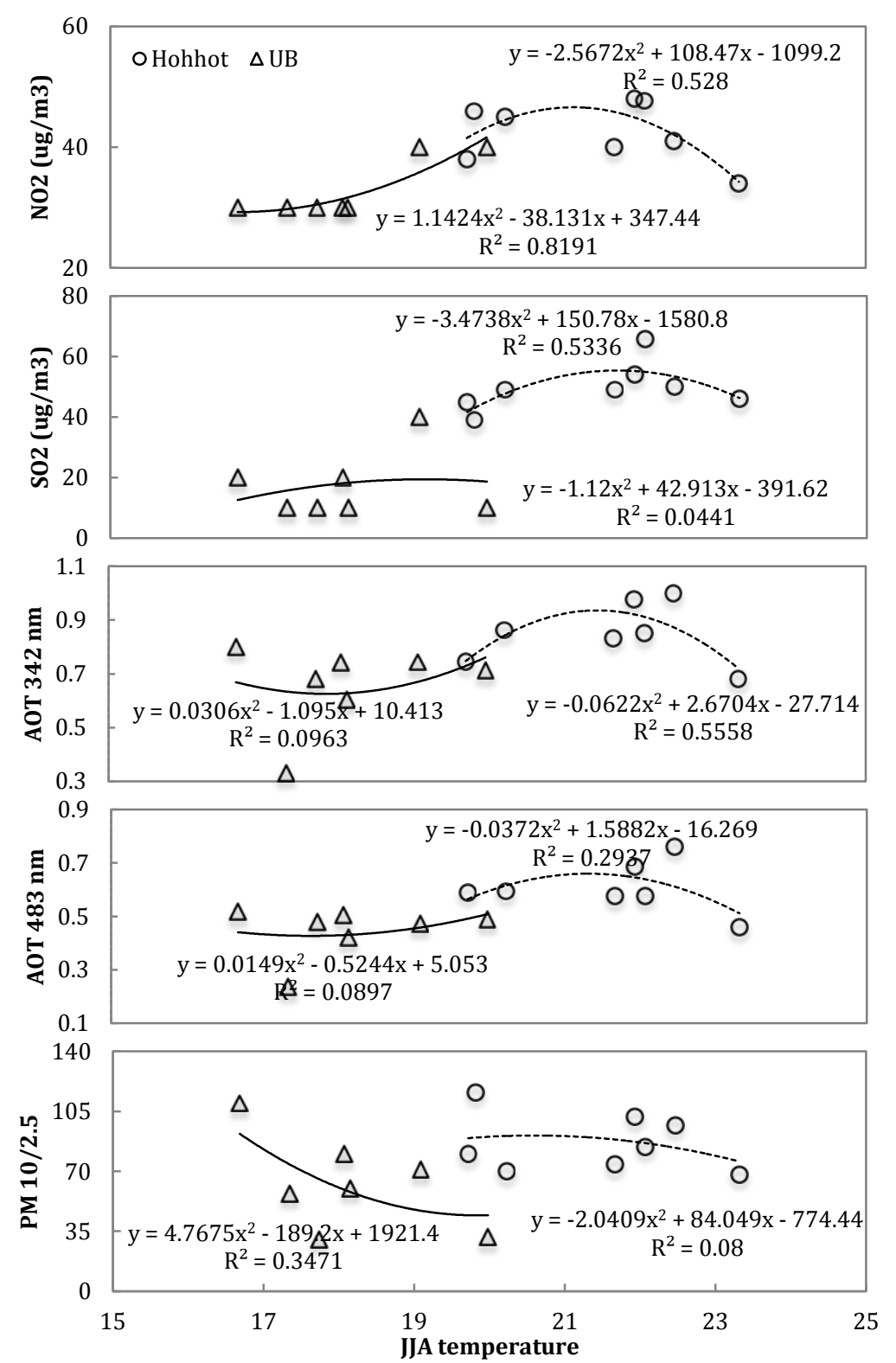
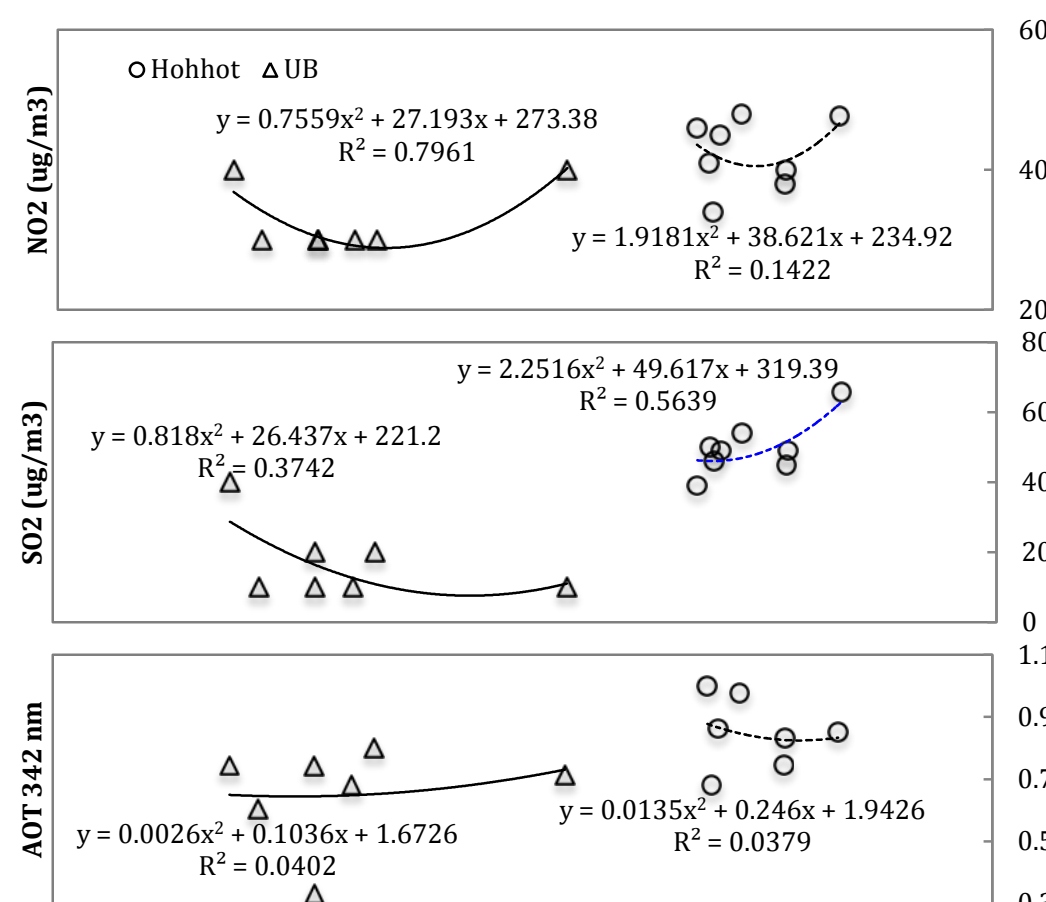

1.1

0.9
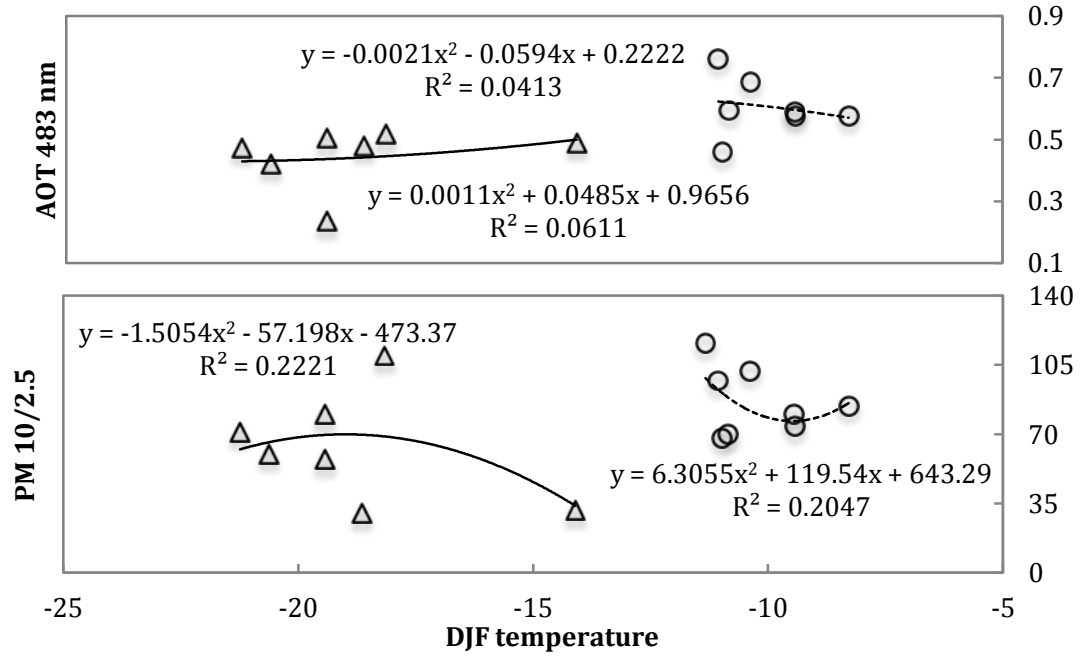

Fig. $9 b$ 

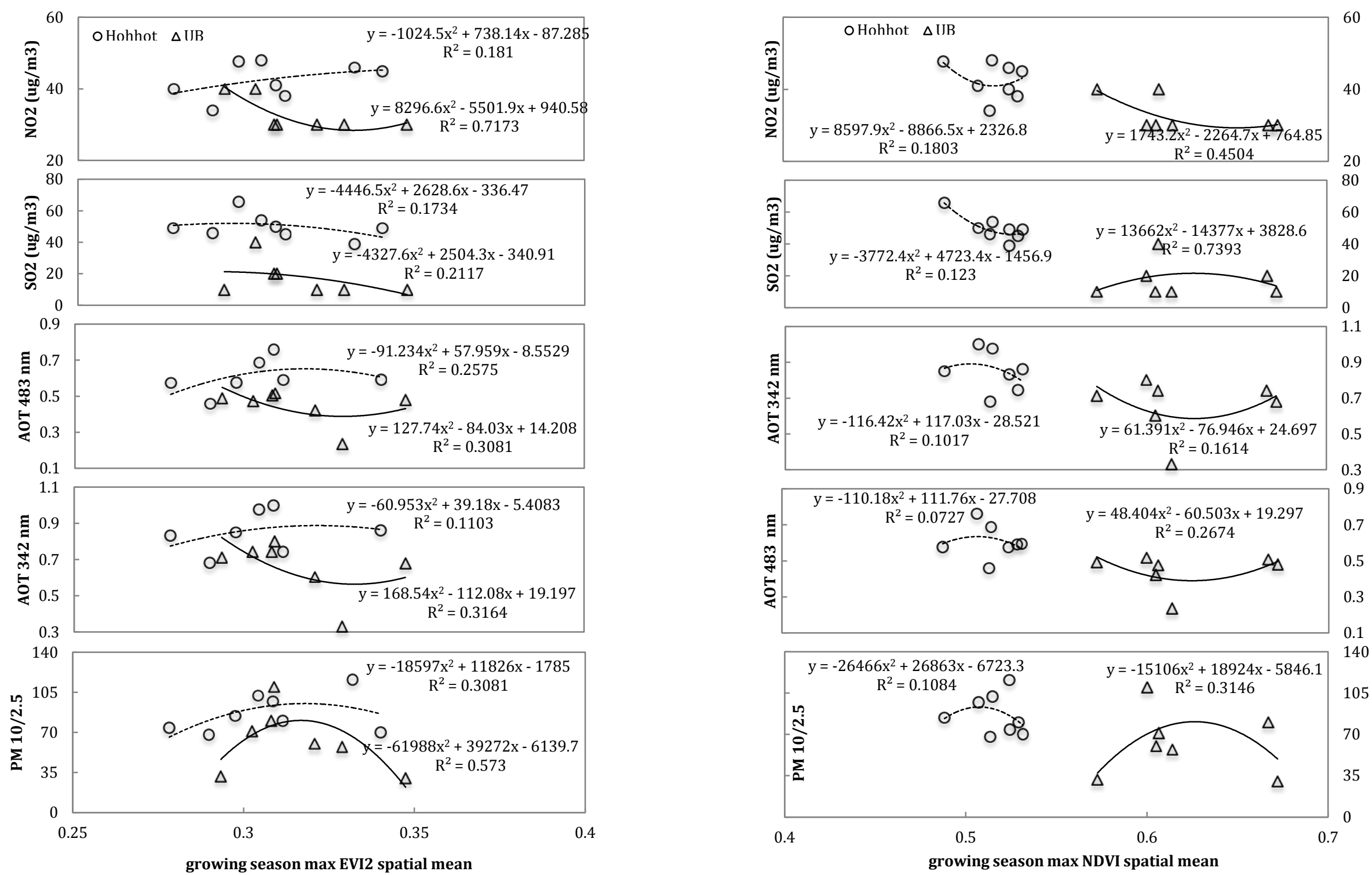

Fig. 9c 

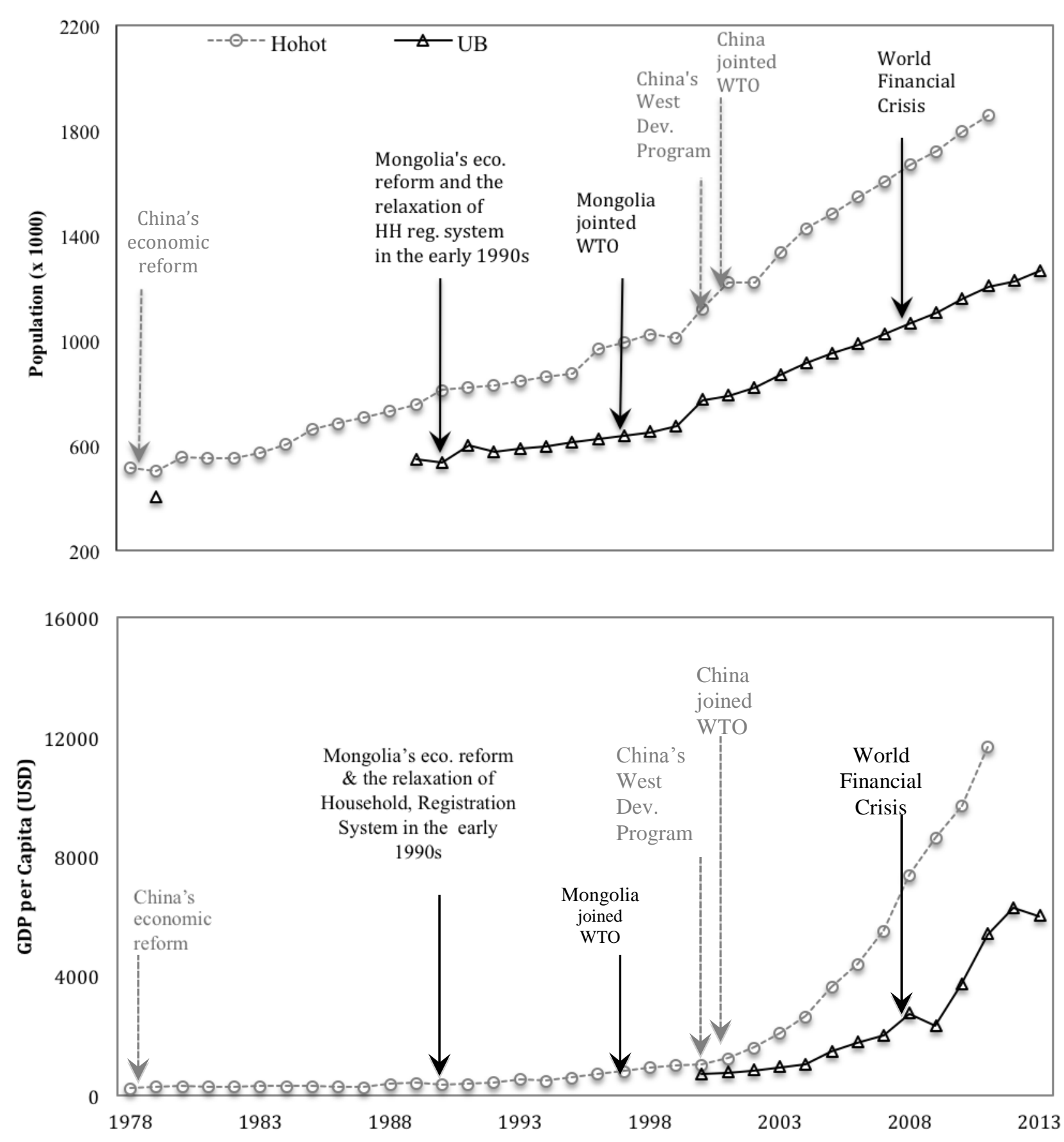

Fig. 10 